\title{
Theory of Structures of Hydrogen-Air Diffusion Flames
}

\author{
A. L. SÁNCHEZ, A. LIÑÁN, F. A. WILLIAMS G. BALAKRISHNAN
}

\begin{abstract}
The structure of the hydrogen-air counterflow diffusion flame is investigated by Damköhlernumber asymptotics. Attention is restricted to flowfield strain times smaller than dissociation times but larger than the characteristic chemical time of three-body recombination reactions, thereby placing the system on the upper, vigorously burning branch of the characteristic $S$-curve of peak temperature as a function of strain time without equilibrium broadening. Under these conditions, it is shown that the reactants can coexist only within a thin reaction zone separating two radical-free equilibrium regions. First, the equations for the counterflow mixing layer in the two outer equilibrium regions are solved in the classical Burke-Schumann limit by the introduction of appropriate conserved scalars that account for variable transport coefficients and variable Schmidt numbers, different for different species. Then, the reaction zone is investigated with scaling that identifies the relevant reduced Damköhler number. While the solutions in the outer zones a re peculiar to the counterflow configuration because of their convective-diffusive character, the reaclive-diffusive nature of the reaction zone at leading order enables its structure in transformed coordinates to be expressed independently of the geometrical configuration. Matching the solutions from the inner reaction region with those from the outer equilibrium regions yields the first-order asymptotic solution to the problem, which compares favorably with results obtained by numerical integration of the full conservation equations with detailed chemistry and transport descriptions. In particular, the reason that the maximum radical concentration and temperature deficit vary linearly with the one-third power of the strain rate is explained.
\end{abstract}

\section{INTRODUCTION}

The study of nonpremixed hydrogen-oxygen combustion is of fundamental importance not only for high-speed propulsion but also because of the relevance of hydrogenoxygen chemistry to hydrocarbon combustion. Much understanding can be obtained by investigating strained laminar flames in steady configurations, such as the counterflow considered here. This understanding can be applied, for example, to the development of laminar flamelet models for nonpremixed turbulent combustion.

Only a few experimental investigations on hydrogen-oxygen diffusion flames are available in the literature. These are mainly concerned with the determination of critical conditions for extinction (Pellet et al., 1991; Pellet et al., 1992; Balakrishnan et al., 1994) and limiting minimum reactant concentrations for the establishment of stable fiames (Ishizuka and Tsuji, 1981). Measurements of temperature and reactant profiles are much more tedious to perform and are reported only in (Trees et al., 1994). Diluted fuel feed is usually required for safety reasons in these laboratory experiments, giving rise to lower radical concentrations. Although laser techniques can fruitfully be applied to measure profiles of concentrations of radicals such as hydroxyl in counterflow diffusion flames, thus far no experimental measurements of minor species profiles have been reported. 
Integration of the full numerical equations in one dimension for the laminar counterflow has become a relatively easy task. Several numerical investigations have appeared recently (Dixon-Lewis and Missaghi, 1988; Gutheil and Williams, 1990; Tangirala et al., 1991; Treviño and Mauss, 1993; Gutheil et al., 1993; Balakrishnan et al., 1995) providing detailed information on various aspects of the flame structure. By way of contrast, the number of theoretical analyses is rather limited. Although the chemistry of hydrogen is fairly simple, the asymptotic structure of the hydrogen-oxygen diffusion flame is less understood than that of hydrocarbons (Treviño and Williams, 1988; Seshadri and Peters, 1988; Chelliah and Williams, 1990). In addition to its own intrinsic interest, the study of this flame and, in particular, its associated radical pool structure is relevant in connection with other analytical investigations, an example being the ongoing study of emissions of $\mathrm{CO}$ and nitrogen oxides in diffusion flames, such as (Hewson and Williams, 1994).

The pioneering analytic work of Clarke and coworkers (Clarke, 1968, 1969; Clarke and Moss, 1970; Allison and Clarke, 1980, 1981) supplied a great deal of valuable information on different aspects concerning realistic chemistry. However, a detailed knowledge of the hydrogen-oxygen kinetic mechanism was not available at the time these analyses were performed, drastically limiting the accuracy of the results obtained. More recent analytical work includes a one-step asymptotic description of the flame derived by introduction of steady-state assumptions for all intermediate species (Gutheil and Williams, 1990), an investigation of flame structure with consideration of crossover temperature influences (Tangirala et al., 1991), a study of extinction with a two-step kinetic scheme (Balakrishnan et al., 1992) and an investigation of different combustion regimes by Damköhler-number and activation-energy asymptotics in the stagnant mixing layer (Lee and Chung, 1994). Although these analyses have expanded our knowledge considerably, a number of open questions concerning the flame structure and its variation as the flow time changes still exist. One such question, to be answered here, is the reason for the difference in the slope of the curve of the maximum $\mathrm{H}$ concentration as a function of the strain rate, obtained by asymptotic analysis (Lee and Chung, 1994) and by numerical integrations.

The present investigation is intended to contribute towards the development of a consistent asymptotic description of the diffusion flame in hydrogen-oxygen systems. Such a description can be useful in studying propagation of triple flames in nonuniform mixtures, stability of diffusion flames and nonpremixed turbulent combustion in reaction-sheet regimes, for example, with real hydrogen-oxygen chemistry. A distinguished limit is identified that applies over a wide range of strain conditions on the upper branch of the $S$-curve of maximum temperature as a function of strain time. A complete asymptotic description of the flame structure is then carried out for this limit, and comparisons with numerical integrations of the full conservation equations with detailed chemistry are made.

\section{FLAME-STRUCTURE CONSIDERATIONS}

Unlike that of most hydrocarbons, the chemistry corresponding to hydrogen-oxygen mixtures is well known (Baulch et al., 1972; Dixon-Lewis and Williams, 1977; Warnatz, 
1984; Smooke, 1991; Baulch et al., 1992) and only uncertainties in the accuracy of some of the reaction-rate parameters remain to be clarified. The chemistry description adopted in the numerical calculations is the 21-step mechanism employed in previous studies (Gutheil and Williams, 1990; Balakrishnan, 1992; Gutheil et al., 1993; Balakrishnan and Williams, 1994; Balakrishnan et al., 1995; Sánchez, 1995) that is shown in Table I, where the most recent version of the reaction-rate constants (Balakrishnan and Williams, 1994) is also included. Substantial simplifications can be achieved in view of previous numerical results (Gutheil and Williams, 1990; Balakrishnan, 1992; Gutheil et al., 1993), which indicate that $\mathrm{H}_{2} \mathrm{O}_{2}$ is negligible, as is $\mathrm{HO}_{2}$ consumption by reverses of three-body recombinations, its concentration being kept small by reactions with radicals. Therefore, only 6 reactive species, namely $\mathrm{H}_{2}, \mathrm{O}_{2}, \mathrm{H}_{2} \mathrm{O}, \mathrm{H}, \mathrm{O}$ and $\mathrm{OH}$, must be considered in determining the flame structure. The chemical-kinetic mechanism then reduces to the shuffle reactions

and

$$
\begin{gathered}
\mathrm{H}+\mathrm{O}_{2} \stackrel{1}{\rightleftharpoons} \mathrm{OH}+\mathrm{O}, \\
\mathrm{H}_{2}+\mathrm{O} \stackrel{2}{\rightleftharpoons} \mathrm{OH}+\mathrm{H}, \\
\mathrm{H}_{2}+\mathrm{OH} \stackrel{3}{\rightleftharpoons} \mathrm{H}_{2} \mathrm{O}+\mathrm{H}
\end{gathered}
$$

along with the three-body recombination reactions

$$
\mathrm{OH}+\mathrm{OH} \stackrel{4}{\rightleftharpoons} \mathrm{H}_{2} \mathrm{O}+\mathrm{O}
$$

and

$$
\begin{gathered}
\mathrm{H}+\mathrm{O}_{2}+\mathrm{M} \stackrel{5 f}{\rightarrow} \mathrm{HO}_{2}+\mathrm{M}, \\
\mathrm{H}+\mathrm{H}+\mathrm{M} \stackrel{6 f}{\rightarrow} \mathrm{H}_{2}+\mathrm{M}, \\
\mathrm{H}+\mathrm{OH}+\mathrm{M} \stackrel{7 f}{\rightarrow} \mathrm{H}_{2} \mathrm{O}+\mathrm{M} \\
\mathrm{O}+\mathrm{OH}+\mathrm{M} \stackrel{8 f}{\rightarrow} \mathrm{HO}_{2}+\mathrm{M},
\end{gathered}
$$

while the recombination reactions $\mathrm{H}+\mathrm{O}+\mathrm{M} \stackrel{9 f}{\rightarrow} \mathrm{OH}+\mathrm{M}$ and $\mathrm{O}+\mathrm{O}+$ $\mathrm{M} \stackrel{10 f}{\rightarrow} \mathrm{O}_{2}+\mathrm{M}$ can always be neglected. Questions concerning concentration profiles of $\mathrm{HO}_{2}$ and $\mathrm{H}_{2} \mathrm{O}_{2}$ can be addressed as perturbations without affecting the present analysis or results but will not be considered further here.

Three different characteristic times can then be identified: a flowfield or strain time (the inverse $a_{\infty}^{-1}$ of the air-side strain rate of the approaching streams being one appropriate selection for this time) and two chemical times associated with the shuffle and recombination reactions, respectively. At very low strain rates the reverse of the recombination reactions can no longer be neglected, thereby introducing a fourth characteristic time, a dissociation time, giving rise to equilibrium broadening (Clarke, 1968), but this very low-strain regime is usually inaccessible experimentally and is not addressed here.

The characteristic time associated with the forward reaction 1 , for example, can be taken to be $\left(k_{1 f} C_{M}\right)^{-1}$, where the $k$ 's denote specific reaction-rate constants, and $C_{M}$ is the total number of moles per unit volume. The characteristic time corresponding to the three-body recombination step 5 can similarly be defined as $\left(k_{5 f} C_{M}^{2}\right)^{-1}$. Typical values of the characteristic times evaluated in this way at atmospheric pressure and at the normal fuel-air adiabatic flame temperature are $10^{-7}$ and $10^{-4}$ seconds for shuffle 
and recombination reactions, respectively. This clearly indicates that the shuffle reactions are much faster than recombination at high enough temperatures and can be assumed to maintain partial equilibrium, as was done previously by Bilger (1980). This assumption provides three independent algebraic relationships among the concentrations of different reactive species, which are given below in Equations 25-27, and results in only three of the four steps $1-4$ being linearly independent.

For strain times larger than the three-body recombination time, radical recombination takes place in a small region, and the mixing layer can then be divided into two radical-free outer layers and a thin reaction layer. A key observation is that, because of the partial equilibrium of the shuffle reactions, in the absence of radicals the reactants cannot coexist, and the Burke-Schumann limit emerges for the description of the outer regions; that is, if $Y_{\mathrm{H}}=Y_{\mathrm{O}}=Y_{\mathrm{OH}}=0$, then the solution to Equations 25-27 yields $Y_{\mathrm{H}_{2}}=0$ or $Y_{\mathrm{O}_{2}}=0$, with $Y_{i}$ denoting the mass fraction of species $i$. This asymptotic structure applies when the strain time lies between the dissociation time, typically 1 second, and the recombination time. As the strain time approaches the latter, the size of the pool of radicals grows as a consequence of insufficiently rapid recombination, resulting in a significant temperature decrease through the radical energy content, thereby causing the partial-equilibrium assumption for the shuffle reactions eventually to lose accuracy through the reduced shuffle rates at low temperatures, ushering in a regime of flame extinction that has been addressed previously (Chung and Williams, 1990; Balakrishnan et al., 1992) but that is not considered here. The present analysis thus is focused on the regime in which the strain time lies between the dissociation time and the recombination time, the most readily accesible regime experimentally.

The computation of hydrogen-air diffusion flames can be considerably simplified if one exploits the presence of the three-layer structure identified above. Solution of the convective-diffusive regions in the Burke-Schumann limit provides the basic flame structure. Integration of the conservation equations is facilitated by the introduction of generalized coupling functions (Liñán and Williams, 1993), which are particularly useful when dealing with complex flow fields, where the flame location must be obtained as part of the solution (Liñan et al., 1994). The solution in the outer regions yields in particular the peak values of the temperature and product concentration, as well as the gradients of reactant concentrations and temperature at the flame.

Consideration of finite-rate effects requires solution of the inner reactive-diffusive region, which gives radical concentrations along with the perturbations to the reactant and temperature profiles. While the structure of the outer equilibrium regions depends upon the particular flow field considered, that of the inner reaction region is universal when expressed in the appropriate transverse coordinate. Therefore, although the present study is devoted to the counterflow configuration, the reaction-layer structure is common to all hydrogen-air diffusion flames under the strain conditions considered here. Correspondingly, the results and equations derived can be applied to simplify the calculation of quantities of interest in complex flow fields; once the basic BurkeSchumann structure is computed, the simple expressions derived below allow us to determine, for instance, the maximum $\mathrm{H}$-atom concentration and the temperature drop from the Burke-Schumann value for a given strain rate. 


\section{FORMULATION}

A steady, axisymmetric, ideal-gas, counterflow configuration is considered, with hydrogen diluted with nitrogen flowing from $y=-\infty$ and air from $y=\infty$. Here, $x$ and $y$ denote the radial and axial coordinates, while $u$ and $v$ are the radial and axial velocity components. Conditions in the inviscid, irrotational outer flows of fuel and oxidizer are denoted by the subscripts $-\infty$ and $\infty$, respectively, and the outer radial velocity is assumed to be proportional to the distance from the axis, i.e., $u_{ \pm \infty}=a_{ \pm \infty} x$, where $a_{ \pm \infty}$ is the strain rate in the outer stream at $\pm \infty$. For this problem, the conservation equations with $N$ different chemical species reduce to the set of ordinary differential equations (Kee et al., 1983; Keyes and Smooke, 1987; Smooke et al., 1988)

Continuity:

$$
\frac{d V}{d y}+2 \rho U=0
$$

$x$-Momentum:

$$
V \frac{d U}{d y}=-\rho U^{2}+\rho_{\infty} a_{\infty}^{2}+\frac{d}{d y}\left(\mu \frac{d U}{d y}\right)
$$

$y$-Momentum:

$$
\frac{d p}{d y}=0
$$

Species:

$$
V \frac{d Y_{i}}{d y}=-\frac{d}{d y}\left(\rho Y_{i} V_{i}\right)+w_{i}
$$

Energy:

$$
V c_{p} \frac{d T}{d y}=\frac{d}{d y}\left(\lambda \frac{d T}{d y}\right)-\sum_{i=1}^{N} h_{i} w_{i}-\rho \sum_{i=1}^{N} c_{p i} Y_{i} V_{i} \frac{d T}{d y} .
$$

In these equations, we have introduced for convenience the functions $U$ and $V$, defined as $u=U x$ and $V=\rho v$. The temperature, pressure, density, thermal conductivity, viscosity and specific heat at constant pressure of the mixture are denoted by $T, p, \rho$, $\lambda, \mu$ and $c_{p}=\sum_{i}^{N} Y_{i} c_{p i}$, respectively, while $V_{i}, w_{i}$ and $c_{p i}$ are the diffusion velocity, mass rate of production and specific heat at constant pressure of species $i$. Here, $h_{i}=h_{i}^{\mathrm{T}}+h_{i}^{0}$ is the enthalpy of species $i$, with $h_{i}^{\mathrm{T}}=\int_{T^{\circ}}^{T} c_{p i} \mathrm{~d} T$ and $h_{i}^{o}$ identifying, respectively, its thermal enthalpy and its enthalpy of formation at $T^{0}$, and $T^{0}$ being a fixed, standard reference temperature. Equations $1-5$ are subject to the boundary conditions

$$
U=a_{\infty}, \quad V=\rho_{\infty} v_{\infty}, Y_{i}=Y_{i \infty}, T=T_{\infty} \quad \text { as } y \rightarrow \infty
$$

and

$$
U=a_{-\infty}=\left(\rho_{-\infty} / \rho_{\infty}\right)^{1 / 2} a_{\infty}, \quad V=\rho_{-\infty} v_{-\infty}, Y_{i}=Y_{i-\infty}, T=T_{-\infty} \quad \text { as } y \rightarrow-\infty
$$


and must be supplemented with the ideal gas law

$$
\rho=\frac{p \bar{W}}{R^{o} T}
$$

where $R^{a}$ is the universal gas constant and $\bar{W}=\left(\sum_{i=1}^{N} Y_{i} / W_{i}\right)^{-1}$ is the mean molecular weight, while $W_{i}$ denotes the molecular weight of species $i$. These equations were integrated numerically by discretizing the spatial differential operators on a mesh of finite length as described in (Giovangigli and Smooke, 1989). A set of multicomponent transport equations for $V_{i}$ is employed in the numerical integrations, with transport properties obtained from the vectorized version of CHEMKIN (Kee et al., 1983; Giovangigli and Darabiha, 1988), which uses NASA polynomial fits to evaluate the thermodynamic and transport data for the multicomponent mixture, with thermal diffusion excluded here. Although thermal diffusion is of some importance in the outer equilibrium zone on the fuel side for diluted flames with low fuel temperatures (Balakrishnan et al., 1995), for simplicity and consistency in comparisons it is omitted here in both the numerical and asymptotic results.

The conservation equations can be simplified by introducing a nondimensional density-weighted coordinate (Williams, 1985), $\eta=\left(2 a_{\infty} \rho_{\infty} / \mu_{\infty}\right)^{1 / 2} \int_{0}^{y} \rho / \rho_{\infty} d y$, and a nondimensional stream function $F(\eta)$, such that $U=a_{\infty} F^{\prime}(\eta)$. In the notation employed here the prime denotes differentiation with respect to $\eta$. The $x$-momentum, species and energy equations reduce to (Sánchez, 1985)

$$
\begin{gathered}
\left(C F^{\prime \prime}\right)^{\prime}+F F^{\prime \prime}+\frac{1}{2}\left(\frac{1}{\bar{\rho}}-F^{\prime 2}\right)=0, \\
-\left(\bar{\rho} Y_{i} \bar{V}_{i}\right)^{\prime}+F Y_{i}^{\prime}=-\frac{\bar{w}_{i}}{\bar{\rho}}
\end{gathered}
$$

and

$$
\left[\frac{C}{P r}\left(\bar{h}^{\mathrm{T}}\right)^{\prime}\right]^{\prime}+F\left(\bar{h}^{\mathrm{T}}\right)^{\prime}-\left(\frac{C}{\operatorname{Pr}} \sum_{i=1}^{N} \bar{h}_{i}^{\mathrm{T}} Y_{i}^{\prime}+\bar{\rho} \sum_{i=1}^{N} \bar{h}_{i}^{\mathrm{T}} Y_{i} \bar{V}_{i}\right)^{\prime}=\sum_{i=1}^{N} \frac{\bar{h}_{i}^{o} \bar{w}_{i}}{\bar{\rho}}
$$

where the nondimensional variables $\bar{\rho}=\rho / \rho_{\infty}, \quad \bar{V}_{i}=\left[\rho_{\infty} /\left(2 a_{\infty} \mu_{\infty}\right)\right]^{1 / 2} V_{i}, \quad \bar{w}_{i}=$ $w_{i} /\left(2 a_{\infty} \rho_{\infty}\right), \bar{h}^{\mathrm{T}}=h^{\mathrm{T}} / h_{\infty}^{\mathrm{T}}$ and $\bar{h}_{i}^{\mathrm{T}}=h_{i}^{\mathrm{T}} / h_{\infty}^{\mathrm{T}}$, and the quantities $\bar{h}_{i}^{o}=h_{i}^{o} / h_{\infty}^{\mathrm{T}}$ have been introduced for convenience, with $h^{\mathrm{T}}=\sum_{i}^{N} h_{i}^{\mathrm{T}} Y_{i}$ denoting the thermal enthalpy of the mixture. Here $\operatorname{Pr}=\mu c_{p} / \lambda$ is the Prandtl number and $C=(\rho \mu) /\left(\rho_{\infty} \mu_{\infty}\right)$ is the ChapmanRubesin parameter. The above equations must be supplemented with a set of transport equations for the diffusion velocities, given below. The boundary conditions for Equations 8, 9 and 10 can be written as $F^{\prime}(+\infty)=1, F(0)=0, F^{\prime}(-\infty)=a_{-\infty} / a_{\infty}=$ $\left(\rho_{\infty} / \rho_{-\infty}\right)^{1 / 2}, Y_{i}(\infty)=Y_{i \infty}, Y_{i}(-\infty)=Y_{i-\infty}, \bar{h}^{\mathrm{T}}(\infty)=1$ and $\bar{h}^{\mathrm{T}}(-\infty)=h_{-\infty}^{\mathrm{T}} / h_{\infty}^{\mathrm{T}}$.

\section{SOLUTION IN THE OUTER EQUILIBRIUM REGIONS}

\section{Governing Equations}

In the present regime, the flow can be divided into two outer convective-diffusive zones where $Y_{\mathrm{O}_{2}}=0$ and $Y_{\mathrm{H}_{2}}=0$, respectively, and a thin inner layer at $\eta=\eta_{\mathrm{F}}$, where the 
overall reaction $2 \mathrm{H}_{2}+\mathrm{O}_{2} \rightarrow 2 \mathrm{H}_{2} \mathrm{O}$ occurs and convection is negligible in the first approximation. In the outer regions only four species are present (three in each), namely, $\mathrm{O}_{2}$, $\mathrm{H}_{2}, \mathrm{H}_{2} \mathrm{O}$ and nitrogen, and the conservation Equations 9 and 10 can be written as

$$
\begin{gathered}
-\left(\bar{\rho} Y_{\mathrm{H}_{2}} \bar{V}_{\mathrm{H}_{2}}\right)^{\prime}+F Y_{\mathrm{H}_{2}}^{\prime}=-\frac{\bar{w}_{\mathrm{H}_{2}}}{\bar{\rho}}, \\
-\left(\bar{\rho} Y_{\mathrm{O}_{2}} \bar{V}_{\mathrm{O}_{2}}\right)^{\prime}+F Y_{\mathrm{O}_{2}}^{\prime}=-\frac{v_{0} \bar{w}_{\mathrm{H}_{2}}}{\bar{\rho}}, \\
-\left(\bar{\rho} Y_{\mathrm{H}_{2} \mathrm{O}} \bar{V}_{\mathrm{H}_{2} \mathrm{O}}\right)^{\prime}+F Y_{\mathrm{H}_{2} \mathrm{O}}^{\prime}=-\frac{\left(v_{o}+1\right) \bar{w}_{\mathrm{H}_{2}}}{\bar{\rho}}
\end{gathered}
$$

and

$$
\left[\frac{C}{\operatorname{Pr}}\left(\bar{h}^{\mathrm{T}}\right)^{\prime}\right]^{\prime}+F\left(\bar{h}^{\mathrm{T}}\right)^{\prime}-\left(\frac{C}{\operatorname{Pr}} \sum_{i=1}^{N} \bar{h}_{i}^{\mathrm{T}} Y_{i}^{\prime}+\bar{\rho} \sum_{i=1}^{N} \bar{h}_{i}^{\mathrm{T}} Y_{i} \bar{V}_{i}\right)^{\prime}=\frac{\left(\nu_{o}+1\right) \bar{h}_{\mathrm{H}_{2} \mathrm{O}} \overline{\mathrm{w}}_{\mathrm{H}_{2}}}{\bar{\rho}},
$$

where $v_{\theta}=8$ is the mass of oxygen consumed per unit mass of fuel, and $\bar{w}_{\mathrm{H}_{2}}$ is identically zero everywhere except at $\eta=\eta_{\mathrm{F}}$, where it is infinitely large. This infinitely large reaction rate results in discontinuities in the gradients of temperature and species concentrations at the flame, where $T$ and $Y_{\mathrm{H}_{2} \mathrm{O}}$ reach their peak values $T^{\mathrm{BS}}$ and $Y_{\mathrm{H}^{2} \mathrm{O}}^{\mathrm{BS}}$, respectively. Equations 8 and 11-14 must be integrated simultaneously subject to the boundary conditions $F^{\prime}(+\infty)=1, F(0)=0, F^{\prime}(-\infty)=a_{-\infty} / a_{\infty}=\left(\rho_{\infty} / \rho_{-\infty}\right)^{1 / 2}$, $Y_{\mathrm{H}_{2}}(\infty)=0, \quad Y_{\mathrm{H}_{2}}(-\infty)=Y_{\mathrm{H}_{2}-\infty}, \quad Y_{\mathrm{O}_{2}}(\infty)=Y_{\mathrm{O}_{2} \infty}, \quad Y_{\mathrm{O}_{2}}(-\infty)=0, \quad Y_{\mathrm{H}_{2} \mathrm{O}}(\infty)=0$, $Y_{\mathrm{H}_{2} \mathrm{O}}(-\infty)=0, \bar{h}^{\mathrm{T}}(\infty)=1$ and $\bar{h}^{\mathrm{T}}(-\infty)=h_{-\infty}^{\mathrm{T}} / h_{\infty}^{\mathrm{T}}$ to find the solution in the outer layers. In particular, integration provides the values of $T^{\mathrm{BS}}$ and $Y_{\mathrm{H}_{2} \mathrm{O}}^{\mathrm{BS}}$ as well as the rate of fuel supply, $\left(Y_{\mathrm{H}_{2}}\right)_{\eta_{E_{k}}^{\prime}}^{\prime}$, and the rate of heat loss towards the air side, $T_{\eta_{F^{*}}^{\prime}}^{\prime}$, which are necessary for matching as shown below.

\section{Useful Transformations and Simplifications}

The integration can be facilitated considerably by the introduction of a set of simplifying assumptions for the flowfield and transport descriptions. In particular, since under all conditions the concentration of water vapor is significantly smaller than that of nitrogen everywhere, the transport of reactants is well described by Fick's law, with nondimensional diffusion velocities given in this formulation by (Sánchez, 1995)

$$
\bar{\rho} Y_{i} \bar{V}_{i}=-C Y_{i}^{\prime} / S_{i} \text {. }
$$

In this equation $S_{i}=\mu /\left(\rho D_{i}\right)$ is the nondimensional Schmidt number for species pair $i$ and $N_{2}$, with $D_{i}$, independent of the mixture composition, being the binary diffusion coefficient corresponding to this species pair. The Chapman-Rubesin parameter $C$, and the nondimensional transport numbers $P r$ and $S_{i}$ depend weakly on temperature, while the mean-molecular-weight $\bar{W}$ variations $S_{i} \propto \bar{W}^{-1 / 2}$ and $C \propto \bar{W}^{3 / 2}$ are significant in these flames and must be taken into account if accurate results are to be obtained. In the first approximation one can neglect the presence of $\mathrm{H}_{2} \mathrm{O}$ and evaluate the viscosity and density as those of a binary mixture of $\mathrm{H}_{2}$ and $\mathrm{N}_{2}$ on the fuel side and of $\mathrm{O}_{2}$ and $\mathrm{N}_{2}$ on the air side, so that Equations 8,11,12 and 14 become independent of $Y_{\mathrm{H}_{2} \mathrm{O}}$ and can be 
integrated separately. An additional simplification results from neglecting the differential diffusion terms in the energy equation, i.e., the third term in Equation 14. This term is identically zero when the specific heat at constant pressure is the same for all the species present in the nixture and also when the diffusivities of all species are equal to the thermal diffusivity. Since these two conditions are closely satisfied for most fuels, this simplification is widely employed. The error introduced by neglecting this term when hydrogen is present was evaluated by Chung and Williams (1990) and found to be relatively small, thereby justifying the adoption of this simplifying assumption. The reactant and energy conservation equations then become

$$
\begin{aligned}
& \left(\frac{C}{S_{\mathrm{H}_{2}}} Y_{\mathrm{H}_{2}}^{\prime}\right)^{\prime}+F Y_{\mathrm{H}_{2}}^{\prime}=-\frac{\bar{w}_{\mathrm{H}_{2}}}{\bar{\rho}}, \\
& \left(\frac{C}{S_{\mathrm{O}_{2}}} Y_{\mathrm{O}_{2}}^{\prime}\right)^{\prime}+F Y_{\mathrm{O}_{2}}^{\prime}=-\frac{y_{o} \bar{w}_{\mathrm{H}_{2}}}{\bar{\rho}},
\end{aligned}
$$

and

$$
\left[\frac{C}{\operatorname{Pr}}\left(\bar{h}^{\mathbf{T}}\right)^{\prime}\right]^{\prime}+F\left(\bar{h}^{\mathbf{T}}\right)^{\prime}=\frac{\left(v_{0}+1\right) \bar{h}_{\mathrm{H}_{2} \mathrm{O}}^{o} \bar{w}_{\mathrm{H}_{2}}}{\bar{\rho}} .
$$

Because of the Dirac-delta character that is associated with the reaction terms in the range of strain conditions considered here, the slopes of the profiles $Y_{i}$ and $\bar{h}^{\mathrm{T}}$ exhibit discontinuities at the flame. A convenient way to handle these discontinuities is to introduce generalized coupling functions (Liñán and Williarns, 1993) $\tilde{Z}$ and $\tilde{H}$, defined below, that account for the different species and thermal diffusivities. The chemistryfree governing equations for these generalized coupling functions are obtained by linear combinations of Equations 16-18. The problem then reduces to that of solving Equation 8 together with

$$
\left(C \tilde{Z}^{\prime}\right)^{\prime}+S_{m} F \tilde{Z}^{\prime}=0
$$

and

$$
\left(C \tilde{H}^{\prime}\right)^{\prime}+\operatorname{Pr} F \tilde{H}^{\prime}+N F \tilde{Z}^{\prime}=0,
$$

where $\tilde{Z}=\left(\tilde{S} \hat{Y}_{\mathrm{H}_{2}}-\hat{Y}_{\mathrm{O}_{2}}+1\right) /(\tilde{s}+1)$ and $\tilde{H}=\hat{Y}_{\mathrm{H}_{2}}+\hat{Y}_{\mathrm{O}_{2}}-1+\left(\bar{h}^{\mathrm{T}}-1\right) / \tilde{q}$, with $\tilde{s}=$ $\left(\widetilde{Y}_{\mathrm{O}_{2}} / \widetilde{S}_{\mathrm{H}_{2}}\right)\left(\widetilde{Y}_{\mathrm{H}_{2}-\infty} / \widetilde{Y}_{\mathrm{O}_{2} \infty}\right) v_{o}$ and $\tilde{q}=\left(\operatorname{Pr} \widetilde{Y}_{\mathrm{H}_{2}-\infty}\right) /\left[S_{\mathrm{H}_{2} \mathrm{~s}}(\tilde{\mathrm{S}}+1)\right]\left(v_{o}+1\right) \bar{h}_{\mathrm{H}_{2} \mathrm{O}} \mathrm{O}$. Here, $\hat{\mathrm{Y}}_{\mathrm{H}_{2}}=$ $\widetilde{Y}_{\mathrm{H}_{2}} / \widetilde{Y}_{\mathrm{H}_{2}-\infty}$ and $\hat{\mathrm{Y}}_{\mathrm{O}_{2}}=Y_{\mathrm{O}_{2}} / Y_{\mathrm{O}_{2} \infty}$ are normalized reactant mass fractions, and $S_{\mathrm{H}_{2} f}$ is the value of $S_{\mathrm{H}_{2}}$ evaluated at the flame. The diffusivity-weighted mass fraction

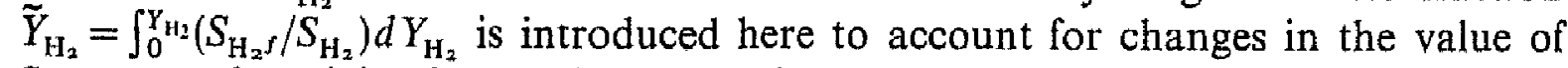
$S_{\mathrm{H}_{3}}$ across the mixing layer. The description of the oxygen diffusion is significantly simpler, in that the variations of mean molecular weight $\bar{W}$ on the oxidizer side are small and, consequently, the value of $S_{\mathrm{O}_{z}}$ remains approximately constant. At the flame, the generalized mixture-fraction variable $\tilde{Z}$ takes on the stoichiometric value $\widetilde{Z}_{s}=1 /(\tilde{s}+1)$. The effective Schmidt number $S_{m}$ and the coefficient $N$ are given by $S_{m}=S_{\mathrm{H}_{2}}$ and $N=\left(S_{\mathrm{H}_{2}}-P r\right)(\tilde{s}+1) / \tilde{s}$ for $\tilde{Z}>\widetilde{Z}_{s}$ and $S_{m}=S_{\mathrm{O}_{2}}$ and $N=\left(P r-S_{\mathrm{O}_{2}}\right)(\tilde{s}+1)$ for $\tilde{Z}<\tilde{Z}_{s}$. Equations 19 and 20 must be integrated subject to the boundary conditions $\tilde{Z}(+\infty)=0, \tilde{Z}(-\infty)=1, \tilde{H}(+\infty)=0$ and $\widetilde{H}(-\infty)=\left(h_{-\infty}^{\mathbf{T}} / h_{\infty}^{\mathrm{T}}-1\right) / \tilde{q}$. Also, because of the translational invariance of the problem, we can locate the flame at $\eta=0$ and replace 
the boundary condition $F(0)=0$ by $\tilde{Z}(0)=\tilde{Z}_{s}$. The distance between the flame and the stagnation plane is then determined from the solution of the problem as the value of $\eta$ at which $F=0$.

Numerical integrations were performed for $\bar{\rho}=1 / \bar{h}^{\mathrm{T}}, \operatorname{Pr}=0.70$, with $C=1$ and $S_{\mathrm{O}_{2}}=0.74$ for $\tilde{Z}<\tilde{Z}_{s}$ and with $C$ and $S_{\mathrm{H}_{2}}$ evaluated as those corresponding to a binary mixture of $\mathrm{H}_{2}$ and $\mathrm{N}_{2}$ for $\tilde{Z}<\tilde{Z}_{s}$, with $S_{\mathrm{H}_{2} f}=0.19$. The above relationship between the density and the thermal enthalpy corresponds to the choice $T^{o}=0$ in the definition of $h^{\mathrm{T}}$ and is strictly valid if the molar specific heats $c_{p i} W_{i}$ of the different chemical species are equal and constant, a condition that is approximately satisfied in gas mixtures at moderate temperatures when all of the species present in the mixture have the same number of atoms. Although those conditions are only partially satisfied in the flow under study, the consequent inaccuracy is not too large, and the significant simplification that this assumption introduces motivates its inclusion in the model.

\section{Results of Integrations and Comparisons with Results of Full Numerical Integrations}

A shooting scheme, with integration initialized at the flame, was employed in the calculations. Details of the application of the same integration method to the solution of a similar counterflow are given by Kim and Williams (1990). Results provide reactant concentration profiles and the value of $\left(Y_{\mathrm{H}_{2}}\right)_{\eta_{\bar{F}}}^{\prime}$ at the flame, necessary for matching, as well as density, enthalpy and flow velocity variations across the mixing layer. Results obtained from the simple flowfield model presented above were compared with those obtained by integration of the full conservation equations with the detailed transport model and a single, infinitely fast reaction adopted for the chemistry. Comparisons are presented in Figure 1, where the solution has been translated to locate the stagnation plane at the origin. Although the simplified model somewhat overpredicts the value of $\eta_{F}$ for all dilution conditions, the shapes of the different profiles and the slopes at the flame, necessary for the analysis of the reaction region, exhibit good agreement. Further attention must be given to the variations of $h^{\mathrm{T}}, \rho$ and the different transport properties with $Y_{\mathrm{H}_{2} \mathrm{O}}$ if more accurate results are to be obtained. This further analysis, which will not be pursued here, would involve introduction of a third generalized coupling function, significantly complicating the calculation. Nevertheless, the model proposed herein is sufficiently accurate for the level of approximation sought in the present study.

Analysis of the reaction region also requires the maximum values of $Y_{\mathrm{H}_{2} \mathrm{O}}$ and $T$ and the slope $\left(T^{\prime}\right)_{\eta_{1}^{+}}$at the flame. The first of these can be evaluated from the BurkeSchumann result $Y_{\mathrm{H}_{2} \mathrm{O}}^{\mathrm{BS}}=Y_{\mathrm{O}_{2} \infty}\left(v_{o}+1\right) / v_{o} \simeq 0.25$, this last value being applicable unless the fuel feed is highly diluted, while the temperature and its slope at the flame can be obtained from the $\bar{h}^{\mathrm{T}}$ profile. Although the presence of water vapor was previously neglected in the flowfield and transport descriptions, the specific heat of $\mathrm{H}_{2} \mathrm{O}$ is considerably larger than that of molecular nitrogen, thereby resulting in a nonnegligible contribution to the thermal enthalpy at the flame that must be taken into account when evaluating the temperature. The value of the maximum temperature in the Burke-Schumann limit is obtained from

$$
\left(\bar{h}^{\mathrm{T}}\right)_{\eta \mathrm{F}}=Y_{\mathrm{H}_{2} \mathrm{O}}^{\mathrm{BS}}\left(\bar{h}_{\mathrm{H}_{2} \mathrm{O}}^{\mathrm{T}}\right)_{\eta \mathrm{F}}+\left(1-Y_{\mathrm{H}_{2} \mathrm{O}}^{\mathrm{BS}}\right)\left(\bar{h}_{\mathrm{N}_{2}}^{\mathrm{T}}\right)_{\eta \mathrm{F}},
$$




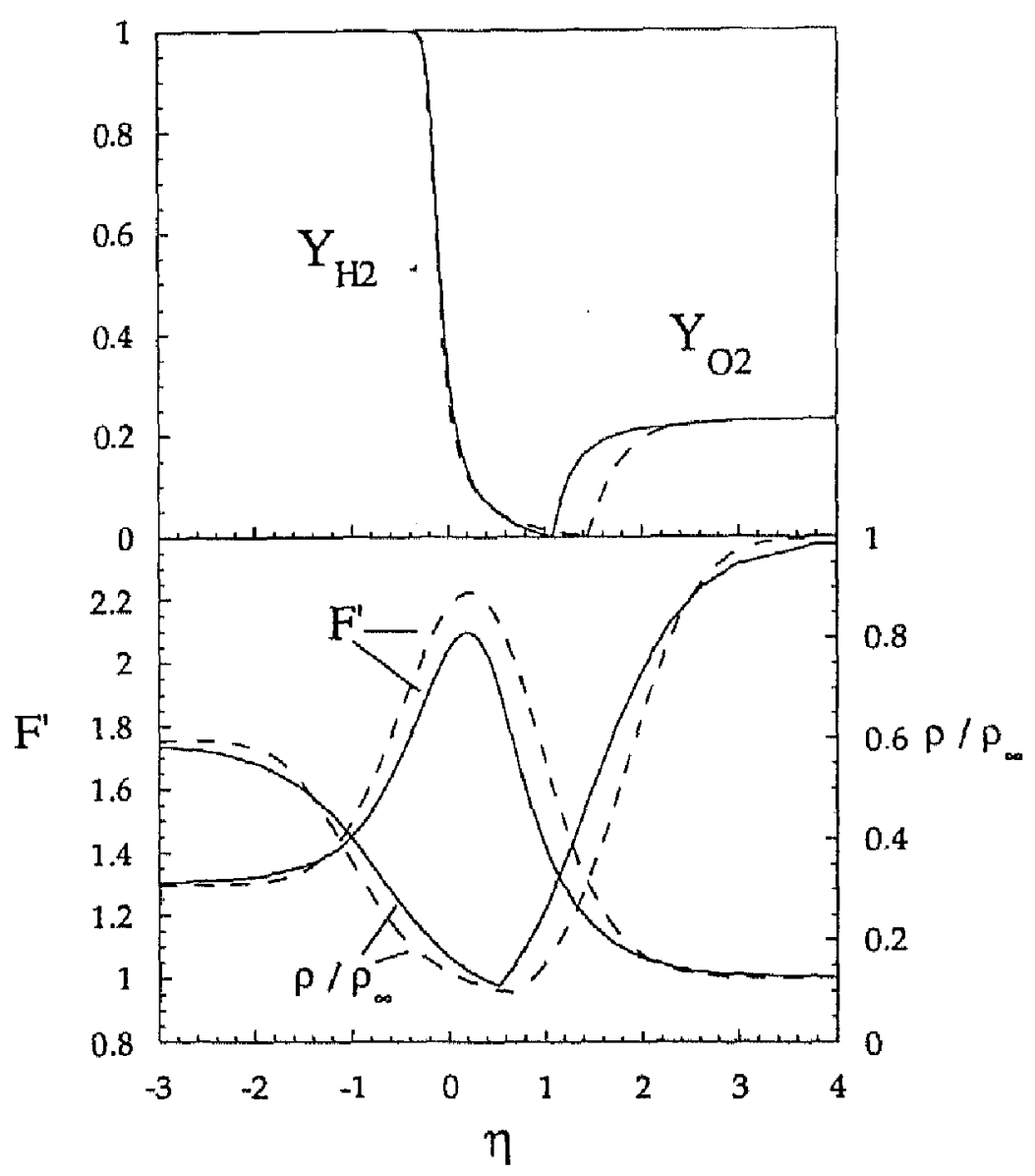

FIGURE 1 The reactant mass-fraction profiles (for $Y_{\mathrm{H}_{2}-\infty}=1.0$ ) and the variations of the nondimensional radial velocity $F^{\prime}$ and of the nondimensional density across the mixing layer (for $Y_{\mathrm{H}_{2}-\mathrm{x}}=0.05$ ), for $T_{x}=T_{-\infty}=300 \mathrm{~K}$ and atmospheric pressure, as obtained from the simplified model (dash lines) and from integration of the full conservation equations (solid lines).

with

$$
\left(\bar{h}_{\mathrm{H}_{2} \mathrm{O}}^{\mathbf{T}}\right)_{\eta F}=\int_{0}^{T^{\mathrm{Bs}}} c_{p \mathrm{H}_{2} \mathrm{O}} d T /\left(\int_{0}^{T_{\sigma}} c_{p N_{2}} d T\right)
$$

and

$$
\left(\bar{h}_{\mathrm{N}_{2}}^{\mathrm{T}}\right)_{\eta_{F}}=\int_{0}^{T^{\mathrm{Rs}}} c_{p \mathrm{~N}_{2}} d T /\left(\int_{0}^{T x} c_{p \mathrm{~N}_{2}} d T\right) .
$$

Similarly, the value of $\left(T^{\prime}\right)_{\eta_{F}^{*}}$ can be estimated in a first approximation from

$$
\left(T^{\prime}\right)_{\eta_{\mathrm{F}}^{*}}=\frac{\int_{0}^{T_{*}} c_{p \mathrm{~N}_{2}} d T}{Y_{\mathrm{H}_{2} \mathrm{O}}^{\mathrm{BS}} c_{p \mathrm{H}_{2} \mathrm{O}}+\left(1-Y_{\mathrm{H}_{2} \mathrm{O}}^{\mathrm{BS}}\right) c_{p \mathrm{~N}_{2}}}\left(\bar{h}^{\mathrm{T}}\right)_{\eta_{\mathrm{F}}}^{\prime} \cdot
$$

Figure 2 compares these approximate values of $Y_{\mathrm{H}_{2} \mathrm{O}}^{\mathrm{BS}}$ and $T^{\mathrm{BS}}$ with those obtained by integration of the full conservation equations in the Burke-Schumann limit. As can be seen, the approximate value of the maximum water vapor fraction is reasonably accurate, except in very dilute flames. The maximum temperature evaluated using 


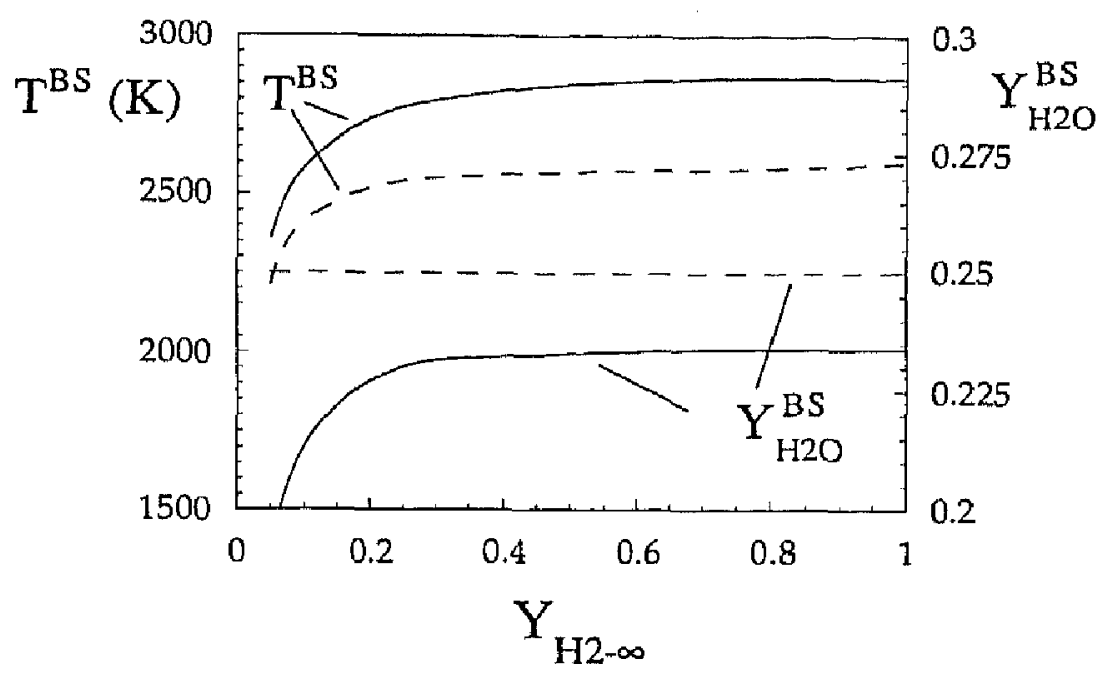

FIGURE 2 The maximum values of $Y_{\mathrm{H}_{2} \mathrm{O}}$ and $T$ in the Burke-Schumann limit as functions of $Y_{\mathrm{H}_{2}-x}$; the dash lines represent the approximate values employed in the analysis, while the solid lines correspond to integration of the full conservation equations.

Equation 21 is approximately $200 \mathrm{~K}$ below that of the full numerical calculations for all dilutions. This is in close agreement with results of a previous analysis (Chung and Williams, 1990) that also neglects the differential diffusion terms in the energy equation. It may be concluded that errors on the order of $10 \%$ may be anticipated from the present formulation under most conditions.

\section{SOLUTION IN THE REACTION REGION}

\section{Equations and Scaling}

The starting species and energy conservation equations in this region are Equations 9 and 10 without the convective terms, with diffusion velocities given by Equation 15 and with the density and transport properties evaluated at the flame. The small parameter of expansion for describing the reaction-zone structure is $\delta$, eventually defined above Equation 31 , and the stretched coordinate $\xi=\left(W_{\mathrm{H}_{2}} L_{\mathrm{H}_{2}} Y_{\mathrm{H}_{2} \mathrm{O}}^{\mathrm{BS}} /\right.$ $\left.W_{\mathrm{H}_{2} \mathrm{O}}\right)^{-1}\left(-Y_{\mathrm{H}_{2}}^{\prime}\right)_{\eta_{\bar{F}}}\left(\eta-\eta_{\mathrm{F}}\right) / \delta$ and dependent variables $y_{i}=\left(W_{i} L_{i} Y_{\mathrm{H}_{2} \mathrm{O}}^{\mathrm{BS}} / W_{\mathrm{H}_{2} \mathrm{O}}\right)^{-1} Y_{i} / \delta$ are introduced for the description of the thin reaction layer, with $L_{i}=\lambda /\left(\rho c_{p} D_{i}\right)$ denoting the corresponding Lewis number. The equations that describe the species concentrations in this region reduce to

$$
\begin{aligned}
& y_{\mathrm{H}}=K_{\mathrm{H}} \delta y_{\mathrm{O}_{2}}^{1 / 2} y_{\mathrm{H}_{2}}^{3 / 2}, \\
& y_{\mathrm{OH}}=K_{\mathrm{OH}} y_{\mathrm{O}_{2}}^{1 / 2} y_{\mathrm{H}_{2}}^{1 / 2},
\end{aligned}
$$

and

$$
y_{\mathrm{O}}=K_{\mathrm{O}} \delta y_{\mathrm{O}_{2}} y_{\mathrm{H}_{2}}
$$


together with

$$
\frac{\mathrm{d}^{2}}{\mathrm{~d} \xi^{2}}\left(2 y_{\mathrm{H}_{2}}-4 y_{\mathrm{O}_{2}}+K_{\mathrm{H}} \delta y_{\mathrm{O}_{2}}^{1 / 2} y_{\mathrm{H}_{2}}^{3 / 2}-K_{\mathrm{OH}_{2}} y_{\mathrm{O}_{2}}^{1 / 2} y_{\mathrm{H}_{2}}^{1 / 2}-2 K_{\mathrm{O}} \delta y_{\mathrm{O}_{2}} y_{\mathrm{H}_{2}}\right)=0
$$

and

$$
\begin{gathered}
\frac{\mathrm{d}^{2}}{\mathrm{~d} \xi^{2}}\left(y_{\mathrm{H}_{2}}-y_{\mathrm{O}_{2}}+K_{\mathrm{H}} \delta y_{\mathrm{O}_{2}}^{1 / 2} y_{\mathrm{H}_{2}}^{3 / 2}\right)= \\
\Lambda \delta^{4}\left(K_{\mathrm{H}} y_{\mathrm{O}_{2}}^{3 / 2} y_{\mathrm{H}_{2}}^{3 / 2}+\gamma_{6} K_{\mathrm{H}}^{2} \delta y_{\mathrm{O}_{2}} y_{\mathrm{H}_{2}}^{3}+\gamma_{7} K_{\mathrm{H}} K_{\mathrm{OH}_{1}} y_{\mathrm{O}_{2}} y_{\mathrm{H}_{2}}^{2}+\gamma_{8} K_{\mathrm{O}} K_{\mathrm{OH}_{\mathrm{H}}} y_{\mathrm{O}_{2}}^{3 / 2} y_{\mathrm{H}_{2}}^{3 / 2}\right),
\end{gathered}
$$

where parameters scaling the magnitudes of the radical concentrations are $K_{H}=$ $\left(K_{1} K_{2}\right)^{1 / 2} K_{3} L_{\mathrm{O}_{2}}^{1 / 2} L_{\mathrm{H}_{2}}^{3 / 2} / L_{H}, K_{\mathrm{OH}}=\left(K_{1} K_{2}\right)^{1 / 2} L_{\mathrm{O}_{2}}^{1 / 2} L_{\mathrm{H}_{2}}^{1 / 2} / L_{\mathrm{OH}}$ and $K_{\mathrm{O}}=K_{1} K_{3} L_{\mathrm{O}_{2}} L_{\mathrm{H}_{2}} / L_{\mathrm{O}}$. Equations 25-27 correspond to partial equilibrium of the shuffle reactions, while Equations 28 and 29 are obtained from linear combinations of the atom and mole conservation equations that eliminate the water vapor concentration. Here $K_{j}$ denotes the equilibrium constant for shuffle reaction $j$, while appropriate rate-ratio parameters for the three-body steps are $\gamma_{6}=k_{6 f} L_{\mathrm{H}} /\left(k_{5 f} L_{\mathrm{O}_{2}}\right), \gamma_{7}=k_{7 f} L_{\mathrm{OH}} /\left(k_{5 f} L_{\mathrm{O}_{2}}\right)$ and $\gamma_{8}=k_{8 f} L_{\mathrm{O}} L_{\mathrm{OH}} /\left(k_{5 f} L_{\mathrm{O}_{2}} L_{\mathrm{H}}\right)$. The parameter

$$
\Lambda=\left(\frac{W_{\mathrm{H}_{2}} L_{\mathrm{H}_{2}} \mathrm{Y}_{\mathrm{H}_{2} \mathrm{O}}^{\mathrm{BS}}}{W_{\mathrm{H}_{2} \mathrm{O}}}\right)^{3}\left(\frac{\operatorname{Pr} L_{\mathrm{O}_{2}} L_{\mathrm{H}}}{2 L_{\mathrm{H}_{2}}}\right)\left(\frac{\rho}{W_{\mathrm{H}_{2}} C_{\mathrm{M}}}\right)\left(\frac{1}{\left(-Y_{\mathrm{H}_{2}}^{\prime}\right)_{\eta_{\mathrm{p}}}^{2}}\right)\left(\frac{k_{5 j} C_{\mathrm{M}}^{2}}{a_{\infty}}\right)
$$

is a Damköhler number constructed as the ratio of the strain time to the characteristic time for radical recombination. The boundary conditions for the above equations are $y_{\mathrm{H}_{2}}(+\infty)=y_{\mathrm{O}_{2}}(-\infty)=0, y_{\mathrm{H}_{2}}(-\infty)=-\xi$ and $y_{\mathrm{O}_{2}}(+\infty)=\xi / 2$. Although there exists a certain degree of coupling between Equations 28, 29 and the energy conservation equation, mainly through the temperature dependence of the equilibrium and reactionrate constants and the density, this effect can be neglected in a first approximation in this reaction zone, where temperature changes are small. Hence, we determine the temperature profile in the reaction region after solving for the species concentrations.

In addition to the large Damköhler number, the parameter $K_{\mathrm{H}}$ typically is large and varies between 3 and 13 for temperatures ranging between the Burke-Schumann temperature and the extinction temperature. This is illustrated in Figure 3, where the variations of the parameters $K_{\mathrm{H}}, K_{\mathrm{O}}$ and $K_{\mathrm{OH}}$ with temperature are exhibited. It can be seen that $K_{\mathrm{O}} \simeq 1$, while $K_{\mathrm{OH}}$ varies between 0.8 and 0.1 over that same temperature range. Depending on the relative magnitudes of $\Lambda$ and $K_{\mathrm{H}}$, two different scalings arise. If $K_{\mathrm{H}} \ll \Lambda^{1 / 3}$, then Equation 29 suggests that the appropriate choice for $\delta$ is $\left(\Lambda K_{\mathrm{H}}\right)^{-1 / 4}$, $K_{\mathrm{OH}}$ must be retained in Equation 28 , and only $\gamma_{6}$, the $2 \mathrm{H} \rightarrow \mathrm{H}_{2}$ recombination, can be neglected in Equation 29 in the first approximation. However, this scaling is limited to very small values of the strain rate. As the strain rate increases, $K_{\mathrm{H}}$ also increases, and it becomes appropriate to consider the distinguished limit in which $\varphi \equiv K_{\mathrm{H}} \Lambda^{-1 / 3}$ is of order unity. Introducing this quantity, choosing $\delta=\Lambda^{-1 / 3}$ and taking into account the fact that $K_{\mathrm{oH}} \ll 1$ we can rewrite the twice-integrated Equation 28 and Equation 29 as

$$
2 y_{\mathrm{H}_{2}}-4 y_{\mathrm{O}_{2}}+\varphi y_{\mathrm{O}_{2}}^{1 / 2} y_{\mathrm{H}_{3}}^{3 / 2}=-2 \xi
$$


$\mathrm{T}[\mathrm{K}]$

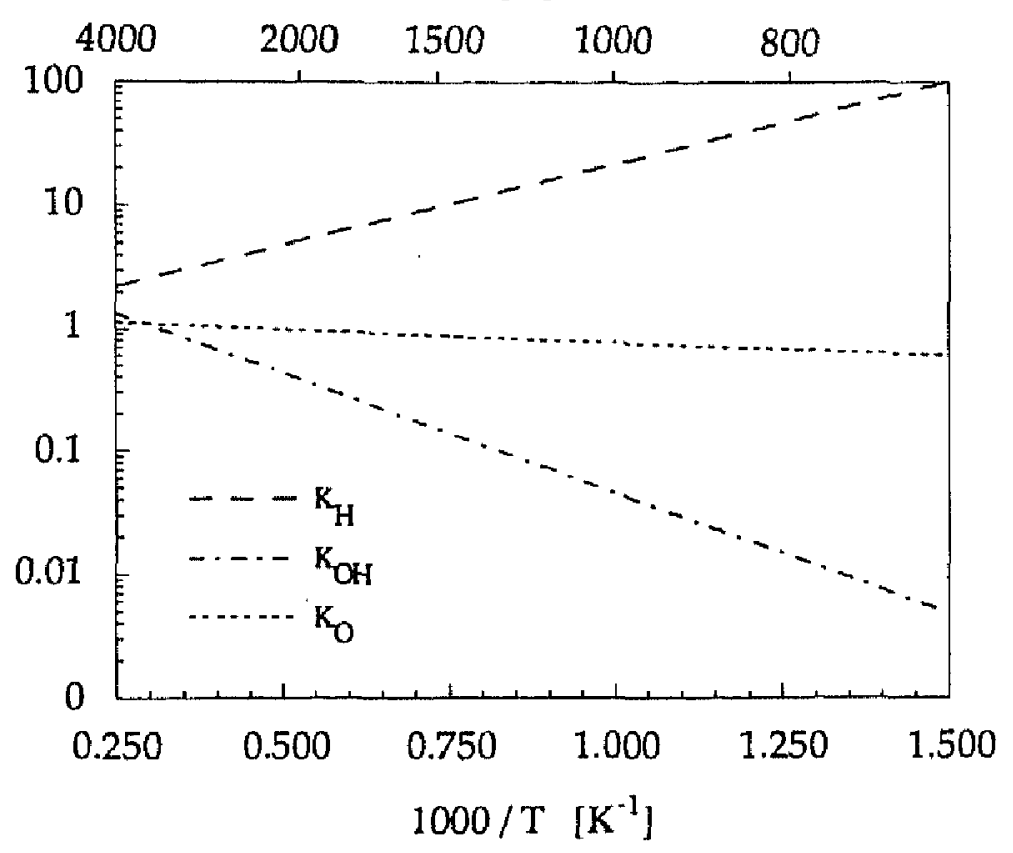

FIGURE 3 The variations of the constants $K_{\mathrm{H}}, K_{\mathrm{O}}$ and $K_{\mathrm{oft}}$ with temperature.

and

$$
\frac{\mathrm{d}^{2}}{\mathrm{~d} \xi^{2}}\left(-y_{\mathrm{H}_{2}}+3 y_{\mathrm{O}_{2}}\right)=\varphi y_{\mathrm{O}_{2}}^{3 / 2} y_{\mathrm{H}_{2}}^{3 / 2}+\gamma_{6} \varphi^{2} y_{\mathrm{O}_{2}} y_{\mathrm{H}_{2}}^{3},
$$

to leading order, then study the evolution of the reaction-layer structure as $\varphi$ increases. Here

$$
\varphi=K_{\mathrm{H}}\left(\frac{W_{\mathrm{H}_{2}} L_{\mathrm{H}_{2}} Y_{\mathrm{H}_{2} \mathrm{O}}^{\mathrm{HS}}}{W_{\mathrm{H}_{2} \mathrm{O}}}\right)^{-1}\left(\frac{\operatorname{Pr} L_{\mathrm{O}_{2}} L_{\mathrm{H}}}{2 L_{\mathrm{H}_{2}}} \frac{\rho}{W_{\mathrm{H}_{2}} C_{\mathrm{M}}} \frac{1}{\left(-Y_{\mathrm{H}_{2}}^{\prime}\right)_{\eta_{\bar{F}}}^{2}} \frac{k_{5 f} C_{\mathrm{M}}^{2}}{a_{\infty}}\right)^{-1 / 3}
$$

is a rescaled measure of the $\mathrm{H}$-atom concentration, appropriate in this subregime that will be seen to extend over a wide range of experimentally accessible conditions. The most relevant Damköhler number for this subregime is $\varphi^{-3}$ because, except for $\gamma_{6}$, discussed below, the system has now been reduced to a one-parameter problem in the single parameter $\varphi$, although since $\delta=\Lambda^{-/ 13}$, for the original scalings defining nondimensional variables the relevant Damköhler number remains $\Lambda$. The only remaining significant recombination steps, at leading order, are 5 and 6 , the latter relevant only rather far on the fuel side, as discussed below.

\section{Numerical Solution and Results}

Because of the considerably larger third-body effectiveness of $\mathrm{H}_{2} \mathrm{O}$, when evaluating the Damköhler number $\Lambda$ and the parameter $\gamma_{6}=0.07$, the latter being a quantity only weakly dependent on temperature, the different Chaperon efficiencies of the chemical species present at the flame must be considered if accurate results are to be obtained. 
Equations 31 and 32, with the boundary conditions previously stated, were solved numerically for different values of $\varphi$ by means of a shooting scheme, as described in an appendix.

The results, presented in Figure 4, show fairly rapid radical removal on the air side through recombination step 5. However, the results indicate that on the fuel side of the reaction layer, where $\mathrm{O}_{2}$ is present only in small concentrations and radical recombination occurs primarily through reaction 6 , the small value of $\gamma_{6}$ results in a slowly decaying $\mathrm{H}$-atom profile, with asymptotic behavior given for large negative $\xi$ by $y_{\mathrm{H}} \simeq 3 /\left(\gamma_{6} \xi^{2}\right)$, as may be derived from Equations 31 and 32 with $y_{\mathrm{H}_{2}}=-\xi$ and step 5 neglected. This clearly indicates that radicals diffuse far into the fuel stream, an effect also observed in previous numerical studies (Dixon-Lewis and Missaghi, 1988; Tangirala et al., 1991). For many purposes, the fuel-side recombination through step 6 can be neglected entirely without making errors that are exceedingly large (Chung and Williams, 1990; Balakrishnan et al., 1992).

The Limit of Small Rescaled Damköhler Number

Simplifications to Equations 31 and 32 can be derived for small and large values of $\varphi$. For small $\varphi$, that is, a large rescaled Damköhler number, recombination takes place in

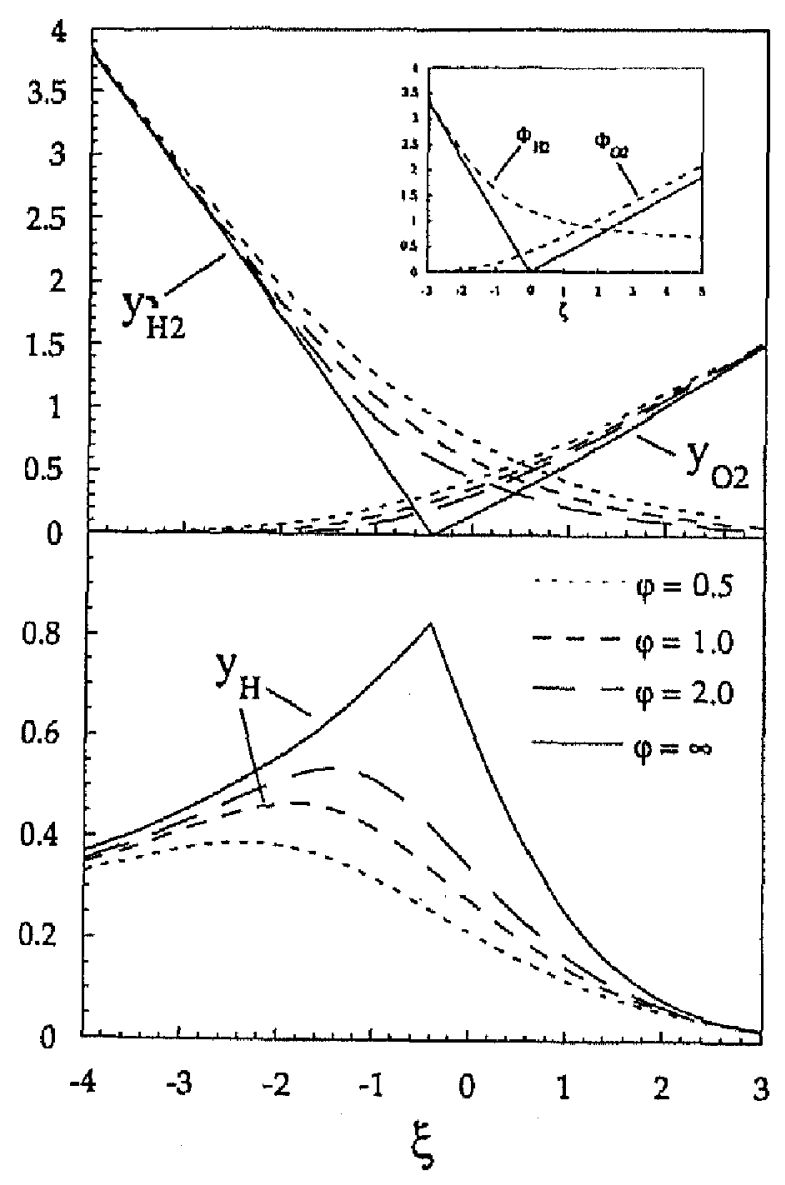

FIGURE 4 The profiles of $y_{\mathrm{H}_{2}}, y_{\mathrm{O}_{2}}$ and $y_{\mathrm{H}}=\varphi y_{\mathrm{O}_{3}}^{1 / 2} y_{\mathrm{H}_{2}}^{3 / 2}$ for different values of the parameter $\varphi$; the inset shows the variations of the functions $\Phi_{\mathrm{H}_{2}}$ and $\Phi_{\mathrm{O}_{2}}$ across the radical-production layer. 
a wide region of characteristic thickness $\varphi^{-1 / 4}$ in the coordinate $\xi$. The solution, which corresponds to the limit $K_{\mathrm{H}} \ll \Lambda^{1 / 3}$ previously identified before Equation 31, requires introduction of new compressed variables $\varphi^{1 / 4} y_{i}$ and $\varphi^{1 / 4} \xi$. In this limit, previously considered by Lee and Chung (1994), the concentration of $H$ in Equation 31 and the recombination through step 6 in Equation 32 can be neglected at leading order. As previously mentioned, more accurate results in this case can be obtained if the concentration of $\mathrm{OH}$ and the three-body recombination reactions 7 and 8 are retained, as may be deduced from Equations 28 and 29 in the limit $K_{\mathrm{H}} \ll \Lambda^{1 / 3}$.

In the limit $\varphi \rightarrow \infty$, for strain rates small enough that $\Lambda \gg 1$ but large enough to make $\varphi \gg 1$, the reaction zone, still a thin layer of characteristic thickness $\Lambda^{-1 / 3}$, can be further divided into left and right recombination layers, where $y_{\mathrm{O}_{2}}=0$ and $y_{\mathrm{H}_{2}}=0$, respectively, and a thin production layer, of characteristic thickness $\Lambda^{-1 / 3} \varphi^{-1 / 2}$, where $\mathrm{H}$ atoms are generated by a mechanism sustained by the shuffle reactions. In the production layer, located at $\xi=\xi_{c}$, the concentration of $\mathrm{H}$ reaches its maximum value $y_{\mathrm{H}_{\mathrm{c}}}$, to be determined. Equation 31 can be evaluated in the radical-production layer to show that

$$
y_{\mathrm{H}_{c}}=-2 \xi_{\mathrm{c}} .
$$

In the left recombination layer, Equations 31 and 32 reduce to $y_{\mathrm{H}_{2}}=-\xi-y_{\mathrm{H}} / 2$ and $\ddot{y}_{\mathrm{H}}=2 \gamma_{6} y_{\mathrm{H}}^{2}$, with boundary conditions $y_{\mathrm{H}}(-\infty)=0$ and $y_{\mathrm{H}}\left(\xi_{c}\right)=y_{\mathrm{H}_{\mathrm{c}}}$, the dot denoting differentiation with respect to $\xi$; a first quadrature yields

$$
\left(\dot{y}_{\mathrm{H}}\right)_{\xi_{\bar{c}}^{-}}^{2}=\frac{4}{3} \gamma_{6} y_{\mathrm{Hc}}^{3}
$$

and a second integration gives the radical profile in this layer as $y_{\mathrm{H}}=\left[y_{\mathrm{Hc}}^{-1 / 2}-\right.$ $\left.\left(\gamma_{6} / 3\right)^{1 / 2}\left(\xi-\xi_{c}\right)\right]^{-2}$. In the right recombination layer the equations reduce to $y_{\mathrm{O}_{2}}=$ $\xi / 2+y_{\mathrm{H}} / 4$ and

$$
\ddot{y}_{\mathrm{H}}=\frac{2}{3}\left[\xi+\left(\frac{1}{2}+2 \gamma_{6}\right) y_{\mathrm{H}}\right] y_{\mathrm{H}} \text {, }
$$

with boundary conditions $y_{\mathrm{H}}(+\infty)=0$ and $y_{\mathrm{H}}\left(\xi_{c}\right)=y_{\mathrm{H}_{c}}$. If $\gamma_{6}$ is neglected, then the error in this last equation is less than $20 \%$, while $y_{\mathrm{H}}=y_{\mathrm{IIc}}=$ constant in the left recombination layer.

In the radical-production layer, a coordinate $\zeta=\varphi^{1 / 2}\left(\xi-\xi_{c}\right)$ and variables $\Phi_{\mathrm{H}_{2}}=\varphi^{1 / 2} y_{\mathrm{H}_{2}}$ and $\Phi_{\mathrm{O}_{2}}=\varphi^{1 / 2} y_{\mathrm{O}_{2}}$ are employed, and Equations 31 and 32 become, respectively,

$$
\Phi_{\mathrm{O}_{2}}^{1 / 2} \Phi_{\mathrm{H}_{2}}^{3 / 2}=y_{\mathrm{H}_{c}}
$$

and

$$
\frac{\mathrm{d}^{2}}{\mathrm{~d} \zeta^{2}}\left(-\Phi_{\mathrm{H}_{2}}+3 \Phi_{\mathrm{O}_{2}}\right)=0,
$$

with boundary conditions $\Phi_{\mathrm{H}_{2}}(-\infty)=-\left[1+\left(\dot{y}_{\mathrm{H}}\right)_{\zeta \bar{\varepsilon}} / 2\right] \zeta, \Phi_{\mathrm{O}_{2}}(-\infty)=0, \Phi_{\mathrm{H}_{2}}(+\infty)=$ 0 and $\Phi_{\mathrm{O}_{2}}(+\infty)=\left[1+\left(\dot{y}_{\mathrm{H}}\right)_{\xi_{e}} / 2\right] \zeta / 2$. A first integration of Equation 38 between $\pm \infty$ 
provides the jump condition

$$
\left(\dot{y}_{\mathrm{H}}\right)_{\xi}-\frac{3}{2}\left(\dot{y}_{\mathrm{H}}\right)_{\xi,}=1
$$

The reactant concentration profiles across the production layer are finally obtained by solving the implicit algebraic equation

$$
\Phi_{\mathrm{O}_{2}}^{1 / 2}\left\{3 \Phi_{\mathrm{O}_{2}}-\left[1+\left(\dot{y}_{\mathrm{H}}\right)_{\xi_{1}} / 2\right]\right\}^{3 / 2}=y_{\mathrm{Hic}}
$$

a quartic for $\Phi_{\mathrm{O}_{2}}$, which is obtained by substitution of the equation

$$
\Phi_{\mathrm{H}_{2}}=3 \Phi_{\mathrm{O}_{z}}-\left[1+\left(\dot{y}_{\mathrm{H}}\right)_{\xi}, 2\right] \zeta \text {, }
$$

determined from a second quadrature of Equation 38, into Equation 37. Integrating now Equation 36 with boundary conditions $y_{\mathrm{H}}\left(\xi_{\mathrm{c}}\right)=y_{\mathrm{Hc}}, \dot{y}_{\mathrm{H}}\left(\dot{\zeta}_{\mathrm{c}}\right)=\left(\dot{y}_{\mathrm{H}}\right)_{\xi}$; and $y_{\mathrm{H}}(+\infty)=0$ along with Equations 34,35 and 39, determines $y_{\mathrm{tc}} \simeq 0.8264$ as an eigenvalue. The resulting $\mathrm{H}$-atom and reactant concentrations for the limit of small released Damköhler number $(\varphi=\infty)$ are shown as solid curves in Figure 4. Also, the functions $\Phi_{\mathrm{H}_{2}}$ and $\Phi_{\mathrm{O}_{2}}$ and their corresponding asymptotes as $\zeta \rightarrow \mp \propto$, namely $-\left[1+\left(\dot{y}_{\mathrm{H}}\right)_{\xi_{\mathrm{r}}} / 2\right] \zeta$ and $\left[1+\left(\dot{y}_{\mathrm{H}}\right)_{\xi+} / 2\right] \zeta / 2$, are exhibited in an inset.

\section{Temperature Variations}

To obtain the temperature profile in the reaction layer we introduce a nondimensional temperature deficit $\Theta$ defined as $\Theta=\Lambda^{1 / 3}\left(T^{\mathrm{BS}}-T\right) / T^{\mathrm{BS}}$. A convenient governing equation to determine $\Theta$ in terms of $y_{i}$ can be obtained by combining linearly the species and energy conservation equations written in reaction-region variables and with the dersity, transport properties and specific heat at constant pressure evaluated at the flame to give in a first approximation

$$
\frac{\mathrm{d}^{2}}{\mathrm{~d} \xi^{2}}\left(\Theta-\sum_{i=1}^{N}\left(q_{i}^{0}+q_{i}^{\mathrm{T}}\right) y_{i}\right)=0
$$

where $q_{i}^{o}=\left(W_{i} h_{i}^{o} Y_{\mathrm{H}_{2} \mathrm{O}}^{\mathrm{BS}} / W_{\mathrm{H}_{2} \mathrm{O}}\right) /\left(c_{p} T^{\mathrm{BS}}\right)$ and $q_{i}^{\mathrm{T}}=\left\{W_{i}\left[\left(h_{i}^{\mathrm{T}}\right)^{\mathrm{BS}}-\left(h_{\mathrm{N}_{2}}^{\mathrm{T}}\right)^{\mathrm{BS}}\right] \quad Y_{\mathrm{H}_{2} \mathrm{O}}^{\mathrm{BS}} / W_{\mathrm{H}_{2} \mathrm{O}}\right\} /$ $\left(c_{p} T^{\mathrm{BS}}\right)$. Since $h_{\mathrm{O}_{2}}^{\mathrm{T}} \simeq h_{\mathrm{N}_{2}}^{\mathrm{T}}$ and $Y_{\mathrm{O}}$ and $Y_{\mathrm{OH}}$ are negligibly small in the reaction region, only species $\mathrm{H}_{2} \mathrm{O}, \mathrm{H}_{2}$ and $\mathrm{H}$ must be considered in determining $\Theta$. If the $\mathrm{H}$-atoms conservation equation $2 \ddot{y}_{\mathrm{H}_{2} \mathrm{O}}+2 \ddot{y}_{\mathrm{H}_{2}}+\ddot{y}_{\mathrm{H}}=0$ is utilized to eliminate $y_{\mathrm{H}_{2} \mathrm{O}}$, integration of Equation 42 gives

$$
\Theta=\dot{\Theta}_{\infty} \xi-\left(q_{\mathrm{H}_{2} \mathrm{O}}^{o}+q_{\mathrm{H}_{2}}^{\mathrm{T}}-q_{\mathrm{H}_{2} \mathrm{O}}^{\mathrm{T}}\right) y_{\mathrm{H}_{2}}-\left(\frac{1}{2} q_{\mathrm{H}_{2} \mathrm{O}}^{o}-q_{\mathrm{H}}^{o}+\frac{1}{2} q_{\mathrm{H}_{2} \mathrm{O}}^{\mathrm{T}}-q_{\mathrm{H}}^{\mathrm{T}}\right) y_{\mathrm{H}},
$$

where $\dot{\Theta}_{\infty}=\left[\left(W_{\mathrm{H}_{2}} L_{\mathrm{H}_{2}} Y_{\mathrm{H}_{2} \mathrm{O}}^{\mathrm{BS}} / W_{\mathrm{H}_{2} \mathrm{O}}\right) /\left(Y_{\mathrm{H}_{2}}\right)_{\eta_{\mathrm{F}^{-}}}^{\prime}\right]\left[\left(T^{\prime}\right)_{\eta_{k_{k}}} / T^{\mathrm{BS}}\right]$ is obtained from the solution in the outer equilibrium regions. Furthermore, evaluation of $q_{i}^{\mathrm{T}}$ reveals that $q_{\mathrm{H}_{2} \mathrm{O}}^{\mathrm{T}} \simeq q_{\mathrm{H}_{2}}^{\mathrm{T}} \simeq 2 q_{\mathrm{H}}^{\mathrm{T}}$, so that the temperature profile finally reduces to

$$
\Theta=\dot{\Theta}_{x} \xi-q_{\mathrm{H}_{2} \mathrm{O}}^{o} y_{\mathrm{H}_{2}}-\left(\frac{1}{2} q_{\mathrm{H}_{2} \mathrm{O}}^{o}-q_{\mathrm{H}}^{o}\right) y_{\mathrm{H}}
$$

Substitution of the solutions for $y_{\mathrm{H}_{2}}$ and $y_{\mathrm{H}}$ into the above equation enables the temperature variations across the reaction layer to be computed easily. The results obtained indicate that the minimum of $\Theta$ is practically independent of the value of $\varphi$. This is illustrated in Figure 5, where the temperature deficit $\Theta$ across the mixing layer is 


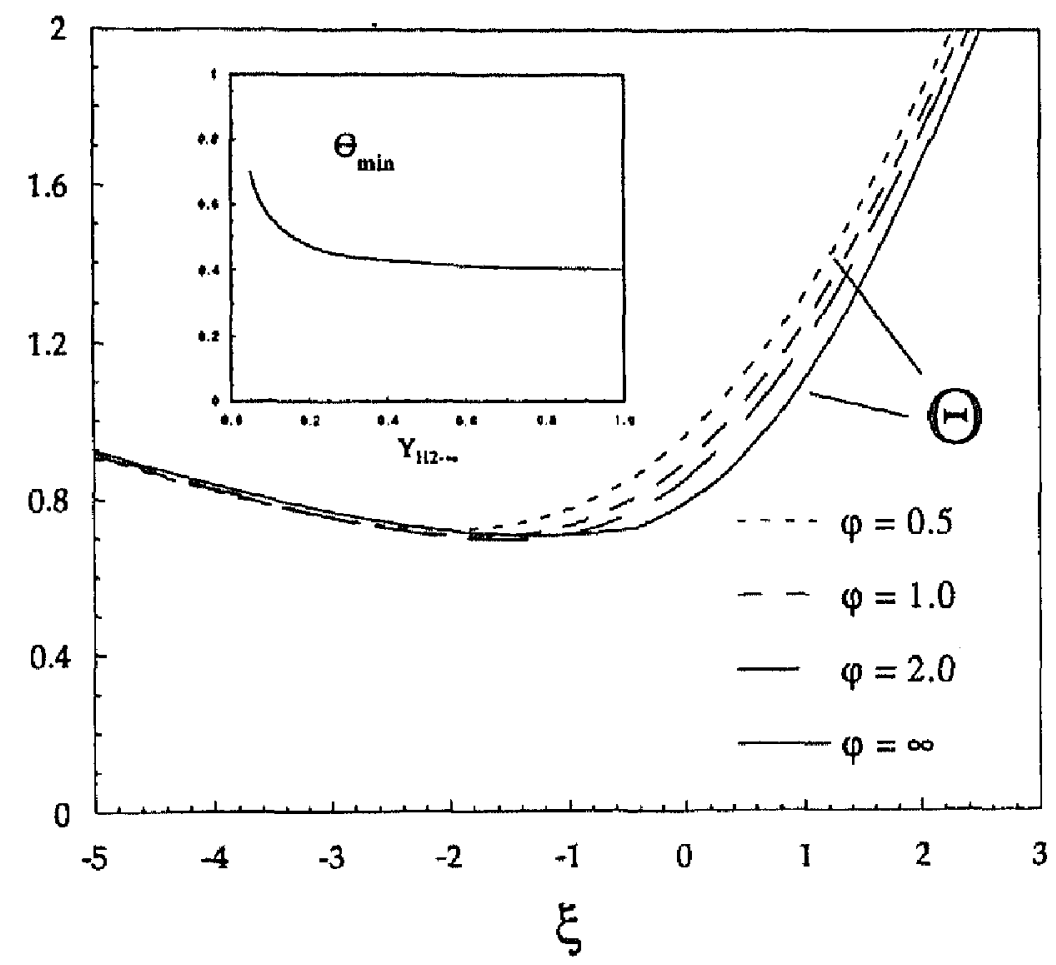

FIGURE 5 The temperature deficit across the reaction layer for different values of $\varphi$ and $Y_{\mathrm{H}_{2}-x}=0.05$, as given by Equation 44; the inset shows the variation of the minimum temperature deficit $\Theta_{\min }$ with $Y_{\mathrm{H}_{2}-\infty}$.

plotted for $Y_{\mathrm{H}_{2}-\infty}=0.05$ and different values of the parameter $\varphi$. Therefore, an excellent estimate of the maximum temperature $T_{\max }$ is obtained from

$$
\frac{T^{\mathrm{BS}}-T_{\max }}{T^{\mathrm{BS}}}=\Lambda^{-1 / 3} \Theta_{\min }
$$

with $\Theta_{\min }$ given as a function of $Y_{\mathrm{H}_{2}-\infty}$ in the inset in Figure 5. As can be seen, $\Theta_{\min } \simeq 0.4$ for $Y_{\mathrm{H}_{2}-\infty}=1.0$ and $\Theta_{\min } \simeq 0.7$ for $Y_{\mathrm{H}_{2}-\infty}=0.05$. It may be noted from this result that, especially in so far as the temperature deficit is concerned, the original Damköhler number $\Lambda$ is a more relevant parameter than the modified Damköhler number $\varphi^{-3}$.

\section{COMPARISONS BETWEEN ASYMPTOTIC AND NUMERICAL RESULTS}

As previously mentioned, combining the results corresponding to the reaction-region analysis with those of a Burke-Schumann calculation provides a simple description of the flame and enables finite-rate effects, such as the rounding of the temperature profile and its associated decrease in maximum temperature, to be accounted for in hydrogenair diffusion flames. For the counterflow configuration, results of Burke-Schumann computations were obtained here with both simplified and detailed equations. Since the results of our analysis are to be compared with numerical results with detailed chemistry and transport, it would be adequate to use the detailed calculation of the 
outer equilibrium regions as the zeroth-order solution. Although we choose to utilize the Burke-Schumann results obtained with our simplified formulation to show that sufficient accuracy emerges, we shall see below that, due to the disagreement in the value of $T^{\mathrm{BS}}$ previously pointed out, use of the detailed Burke-Schumann results is necessary if an accurate prediction of the maximum temperature is to be obtained.

Results of the numerical integrations are compared with those of the asymptotic analysis in Figures 6 and 7, where the maximum H-atom mass fraction and the maximum temperature are plotted as functions of the air-side strain rate for two different dilution conditions. The asymptotic analysis predicts that the maximum H-atom concentration scales linearly with the one-third power of the strain rate, a scaling law clearly exhibited also by the results of the numerical integrations until conditions approach extinction. The value of $Y_{H \max }$ corresponding to the asymptotic analysis, obtained from

$$
Y_{\mathrm{Hmax}}=\left(W_{\mathrm{H}} L_{\mathrm{H}} Y_{\mathrm{H}_{2} \mathrm{O}}^{\mathrm{BS}} / W_{\mathrm{H}_{2} \mathrm{O}}\right) \Lambda^{-1 / 3} y_{\mathrm{H}_{\max }}
$$

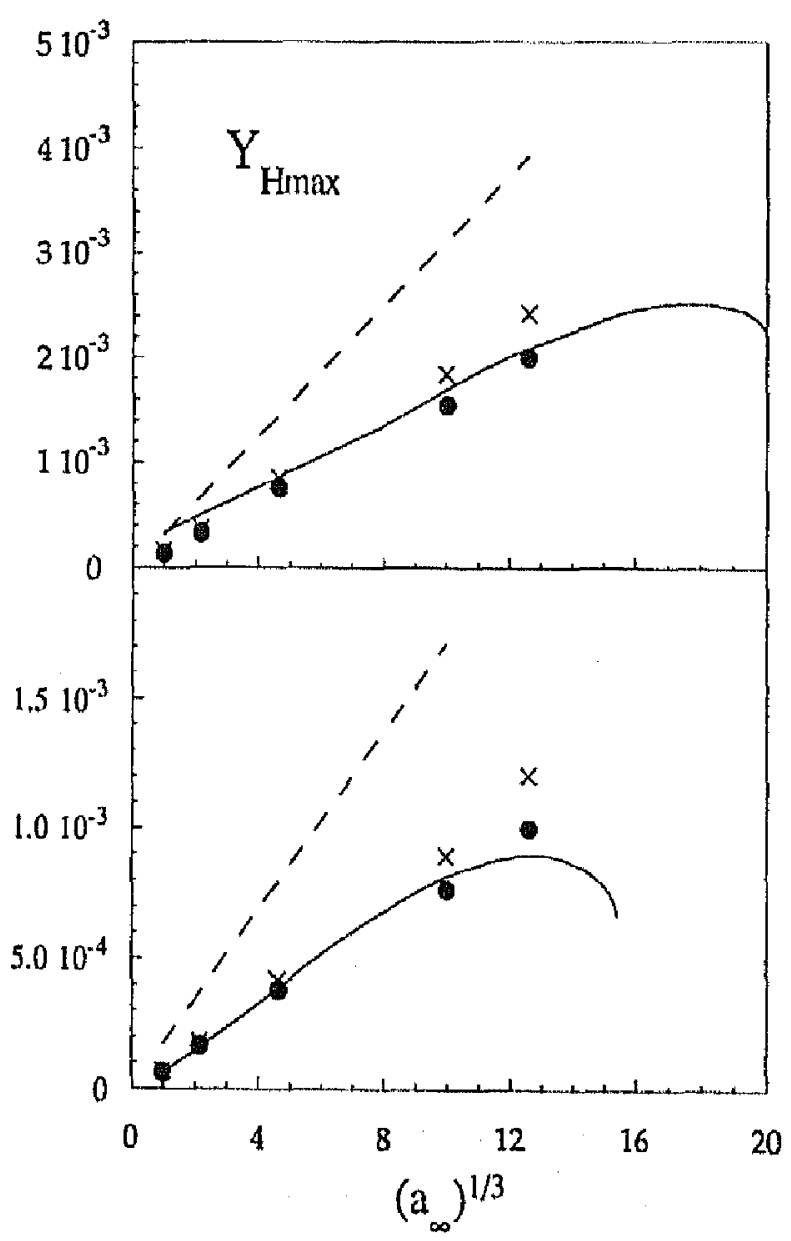

FIGURE 6 The maximum $H$-atom fraction as a function of the strain rate $a_{x}\left(s^{-1}\right)$ for $Y_{H_{s}-x}=1,0$ (above) and for $Y_{\mathrm{H}_{2}-\infty}=0.05$ (below) as obtained from the numerical integration of the full conservation equations with 21-step chemistry (solid lines) and from Equation 46 with $\Lambda=\Lambda_{\mathrm{BS}}$ and $y_{\mathrm{H} \max }=y_{\mathrm{Hc}}$ (broken lines), with $\Lambda$ and $y_{\mathrm{Hmax}}$ evaluated at $T_{\max }$ obtained from Equation 47 (solid dots) and with $\Lambda$ and $y_{\mathrm{H} \max }$ evaluated at $T_{\max }$ obtained from Equation 48 (crosses); with $p=1 \mathrm{~atm}$ and $T_{x_{i}}=T_{-x}=300 \mathrm{~K}$. 


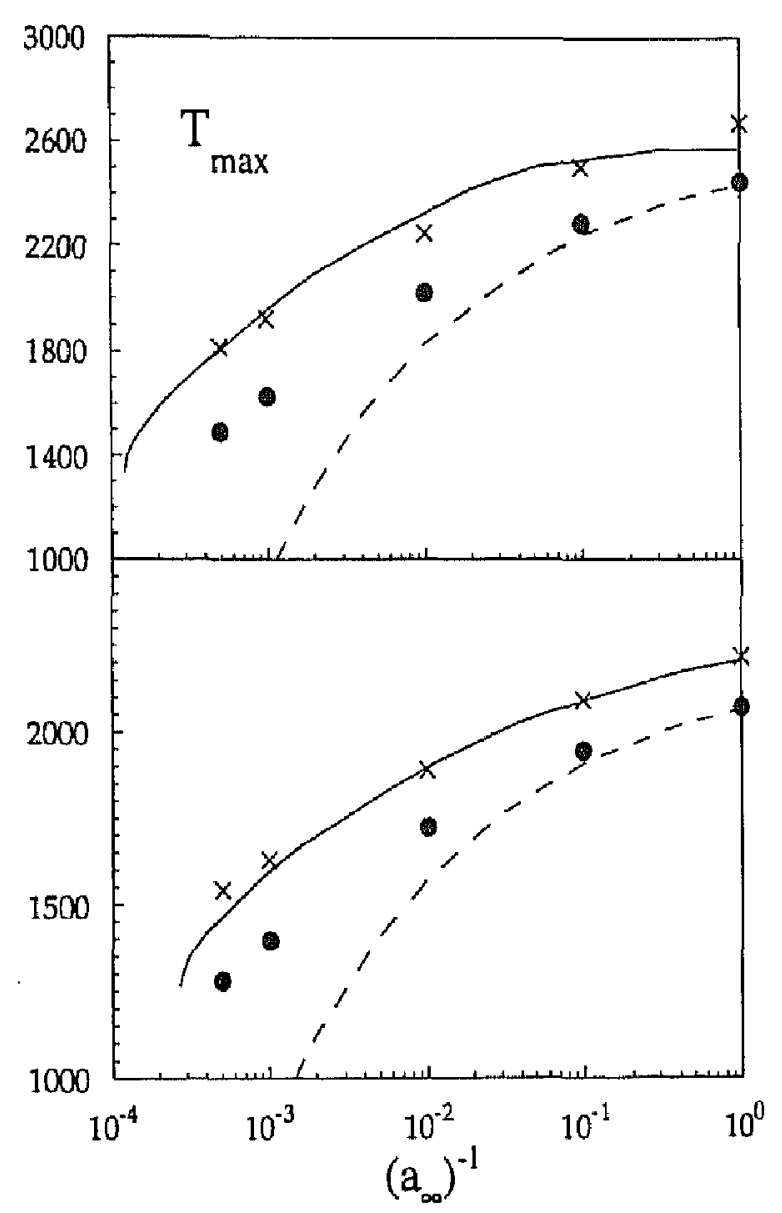

FIGURE 7 The maximum temperature as a function of the strain rate $a_{\infty}\left(s^{-1}\right)$ for $Y_{\mathrm{H}_{2}-\infty}=1.0$ (above) and for $Y_{\mathrm{H}_{2}-x}=0.05$ (below) as obtained from the numerical in tegration of the full conservation equations with 21-step chemistry (solid lines), from Equation 45 with $\Lambda=\Lambda_{\mathrm{BS}}$ (broken lines), from Equation 47 (solid dots) and from Equation 48 with $T^{\mathrm{BS}}$ evaluated with detailed transport (crosses); $p=1 \mathrm{~atm}$ and $T_{\infty}=T_{-\infty}=300 \mathrm{~K}$.

which follows from the definition of $y_{i}$ preceeding Equation 25 and the definition of $\delta$ preceeding Equation 31, was evaluated in three different ways. First it was assumed for simplicity that the maximum value of $y_{\mathrm{H}}$ and the time of radical recombination $\left(k_{5 f} C_{\mathrm{M}}^{2}\right)^{-1}$ in Equation 30 are constants independent of $a_{\infty}$. The former is taken as $y_{\mathrm{Hc}}$, found after Equation 41 for the limit of large $\varphi$, while $\left(k_{5 j} C_{M}^{2}\right)^{-1} \alpha T^{3.42}$ is evaluated at the Burke-Schumann temperature, in strict adherence to leading-order expansions. These simplifications clearly cause an overprediction on the slopes of the curves in Figure 6 at low strain rates, for which $y_{\mathrm{H}} \ll y_{\mathrm{H} c}$, and also at high strain rates, for which $T_{\max } \ll T^{\mathrm{BS}}$. Similarly, when the maximum temperature obtained from Equation 45 is calculated with the time of radical recombination estimated at $T^{\mathrm{BS}}$, relatively large departures from the results of the numerical integrations arise as shown in Figure 7.

Much improvement is obtained when the variations of temperature are taken into account in computing $\Lambda$. The maximum temperature is then determined by solving iteratively the implicit equation

$$
\frac{T_{\max }}{T^{\mathrm{BS}}}=1-\Lambda_{\mathrm{BS}}^{-1 / 3} \Theta_{\min }\left(\frac{T_{\max }}{T^{\mathrm{BS}}}\right)^{3.42 / 3},
$$


where $\Lambda_{\mathrm{BS}}$ is the Damköhler number evaluated at $T^{\mathrm{BS}}$. Equation 47 is obtained from Equations 30 and 45 by introducing the $k_{s f}$ variation indicated above. The curves in Figure 7 obtained in this way, although somewhat below those of the numerical integrations, tend to parallel them, indicating that the asymptotic analysis describes well the variations of temperature with strain time, variations not predicted correctly by less systematic treatments of the chemistry. The offset between the two curves can be attributed to the differences in Burke-Schumann temperatures shown in Figure 2; a more accurate analysis of the equilibrium regions, achieved at the expense of greater numerical effort, results in a smaller shift as shown below. Results obtained from Equation 46 with this modified evaluation of $\Lambda$ and a variable $y_{1+m a x}$, computed from the corresponding value of $\varphi$, show extremely good agreement with numerical results, as can be seen from Figure 6 .

Further improvement of the temperature predictions can be obtained by introducing

$$
\frac{T_{\max }}{T^{\mathrm{BS}}}=\left[1+\Lambda_{\mathrm{BS}}^{-1 / 3} \Theta_{\min }\left(\frac{T_{\max }}{T^{\mathrm{BS}}}\right)^{3.42 / 3}\right]^{-1} .
$$

a modified version of Equation 47. While Equations 47 and 48 are equally valid for large values of the Damköhler number, Equation 48 gives a less pronounced decay of $T_{\max }$ as the strain rate increases, more in accordance with numerical results. The values

\section{TABLE I}

Rate parameters for the hydrogen-oxygen system adopted in the present study; the specific reaction-rate constants $k_{i}$ vary with temperature $T$ according to $k_{i}=A_{i} T^{n i} \exp \left(-E_{i} / R^{\prime} T\right)$

\begin{tabular}{|c|c|c|c|c|c|}
\hline No. & Reactions & $A^{\mathrm{a}}$ & $n^{\mathrm{a}}$ & $E^{\mathrm{a}}$ & Source \\
\hline 1 & $+\mathrm{O}_{2} \rightleftharpoons \mathrm{OH}+\mathrm{O}$ & $3.52 \times 10^{16}$ & -0.7 & 17070 & Mansten et al. (1990) \\
\hline 2 & $\mathrm{H}_{2}+\mathrm{O} \rightleftharpoons \mathrm{OH}+\mathrm{H}$ & $5.06 \times 10^{4}$ & 2.67 & 6290 & Yetter et ul. (1991) \\
\hline 3 & $\mathrm{H}_{2}+\mathrm{OH} \rightleftharpoons \mathrm{H}_{2} \mathrm{O}+\mathrm{H}$ & $1.17 \times 10^{9}$ & 1.3 & 3626 & Baulch et al. (1992) \\
\hline 4 & $\mathrm{OH}+\mathrm{OH} \rightleftharpoons \mathrm{H}_{2} \mathrm{O}+\mathrm{O}$ & \multicolumn{3}{|c|}{$k=5.46 \times 10^{11} \exp (0.00149 \mathrm{~T})$} & Yetter et al. (1991) \\
\hline $5^{b}$ & $\mathrm{H}+\mathrm{O}_{2}+\mathrm{M} \rightleftharpoons \mathrm{HO}_{2}+\mathrm{M}$ & $6.76 \times 10^{19}$ & -1.42 & 0 & Yetter et al. (1991) \\
\hline $6^{c}$ & $\mathrm{H}+\mathrm{H}+\mathrm{M} \rightleftharpoons \mathrm{H}_{2}+\mathrm{M}$ & $1.80 \times 10^{18}$ & -1.0 & 0 & Smooke (1991) \\
\hline $7^{b}$ & $\mathrm{H}+\mathrm{OH}+\mathrm{M} \rightleftharpoons \mathrm{H}_{2} \mathrm{O}+\mathrm{M}$ & $2.20 \times 10^{22}$ & -2.0 & 0 & Baulch et al. (1992) \\
\hline 8 & $\mathrm{O}+\mathrm{OH}+\mathrm{M} \rightleftharpoons \mathrm{HO}_{2}+\mathrm{M}$ & $1.00 \times 10^{16}$ & 0.0 & 0 & Smooke (1991) \\
\hline $9^{b}$ & $\mathrm{H}+\mathrm{O}+\mathrm{M} \rightleftharpoons \mathrm{OH}+\mathrm{M}$ & $6.20 \times 10^{16}$ & -0.6 & 0 & Yetter et al. (1991) \\
\hline $10^{b}$ & $\mathrm{O}+\mathrm{O}+\mathrm{M} \rightleftharpoons \mathrm{O}_{2}+\mathrm{M}$ & $6.17 \times 10^{15}$ & -0.5 & 0 & Yetter et al. (1991) \\
\hline 11 & $\mathrm{H}+\mathrm{HO}_{2} \rightleftharpoons \mathrm{H}_{2}+\mathrm{O}_{2}$ & $4.28 \times 10^{13}$ & 0.0 & 1411 & Baulch et al. (1992) \\
\hline 12 & $\mathrm{HO}_{2} \rightleftharpoons \mathrm{OH}+\mathrm{OH}^{2} \mathrm{H}$ & $1.70 \times 10^{14}$ & 0.0 & 874 & Baulch et al. (1992) \\
\hline 13 & $\mathrm{H}+\mathrm{HO}_{2} \rightleftharpoons \mathrm{O}+\mathrm{H}_{2} \mathrm{O}$ & $3.10 \times 10^{13}$ & 0.0 & 1720 & Baulch et al. (1992) \\
\hline 14 & $\mathrm{O}+\mathrm{HO}_{2} \rightleftharpoons \mathrm{OH}+\mathrm{O}_{2}$ & $2.00 \times 10^{13}$ & 0.0 & 0 & Baulch et al. (1992) \\
\hline 15 & $\mathrm{OH}+\mathrm{HO}_{2} \rightleftharpoons \mathrm{H}_{2} \mathrm{O}+\mathrm{O}_{2}$ & $2.89 \times 10^{13}$ & 0.0 & -497 & Baulch et al. (1992) \\
\hline 16 & $\mathrm{HO}_{2}+\mathrm{HO}_{2} \rightleftharpoons \mathrm{H}_{2} \mathrm{O}_{2}+\mathrm{O}_{2}$ & $3.02 \times 10^{12}$ & 0.0 & 1390 & Yetter et al. (1991) \\
\hline $17^{d}$ & $\mathrm{H}_{2} \mathrm{O}_{2}+\mathrm{M} \rightleftharpoons \mathrm{OH}+\mathrm{OH}+\mathrm{M}$ & $1.20 \times 10^{17}$ & 0.0 & 45500 & Yetter et al. (1991) \\
\hline 18 & $\mathrm{H}_{2} \mathrm{O}_{2}+\mathrm{OH} \rightleftharpoons \mathrm{H}_{2} \mathrm{O}+\mathrm{HO}_{2}$ & $7.08 \times 10^{12}$ & 0.0 & 1430 & Yetter et al. (1991) \\
\hline 19 & $\mathrm{H}_{2} \mathrm{O}_{2}+\mathrm{H} \rightleftharpoons \mathrm{H}_{2} \mathrm{O}+\mathrm{OH}$ & $1.00 \times 10^{13}$ & 0.0 & 3590 & Smooke (1991) \\
\hline 20 & $\mathrm{H}_{2} \mathrm{O}_{2}+\mathrm{H} \rightleftharpoons \mathrm{HO}_{2}+\mathrm{H}_{2}$ & $4.79 \times 10^{13}$ & 0.0 & 7950 & Smooke (1991) \\
\hline 21 & $\mathrm{H}_{2}+\mathrm{O}_{2} \rightleftharpoons \mathrm{OH}+\mathrm{OH}$ & $1.70 \times 10^{13}$ & 0.0 & 47780 & Smooke (1991) \\
\hline
\end{tabular}

aUnits: $\mathrm{mol} / \mathrm{cm}^{3}, \mathrm{~s}^{-1}, \mathrm{~K}, \mathrm{cal} / \mathrm{mol}$; rates for reverse steps obtained from JANAF thermochemical equilibrium data.

${ }^{b}$ Chaperon Efficiencies: $\mathrm{H}_{2}: 2.5, \mathrm{H}_{2} \mathrm{O}: 12.0, \mathrm{O}_{2}: 1.0$ and $\mathrm{N}_{2}: 1.0$

'Chaperon Efficiencies: $\mathrm{H}_{2}: 1, \mathrm{H}_{2} \mathrm{O}: 6.5, \mathrm{O}_{2}: 0.4$ and $\mathrm{N}_{2}: 0.4$

${ }^{2}$ Chaperon Efficiencies: $\mathrm{H}_{2}: 2.5, \mathrm{H}_{2} \mathrm{O}: 15.0, \mathrm{O}_{2}: 1.0$ and $\mathrm{N}_{2}: 1.0$ 
of $T_{\max }$ obtained from Equation 48 with the value of $T^{\mathrm{BS}}$ computed with detailed transport (the solid line in Fig. 2) are plotted in Figure 7. Clearly, Equation 48 is able to reproduce accurately the numerical results over the range of strain conditions studied, indicating that the above modified equation is adequate to extend the asymptotic results to values of $\Lambda$ only moderately large. The small deviation observed at lowest values of $a_{\infty}$ is connected with equilibrium broadening effects, not considered in our analysis. Since the 21-step mechanism shown in Table 1 includes the most important dissociation steps, equilibrium broadening appears in the numerical results for values of $a_{x}^{-1}$ comparable with the dissociation time, so that the maximum temperature approaches a value somew hat lower than $T^{\mathrm{BS}}$ as the strain rate decreases towards zero. The value of $Y_{\mathrm{H}_{\max }}$ evaluated from Equation 46 with the new value of $T_{\max }$ is also shown in Figure 6. As can be seen, the values of the maximum $H$ mass fraction that are obtained are quite close to those previously determined with a less accurate value of $T_{\max }$ suggesting that the computation of $Y_{\mathrm{H}_{\max }}$ is not very sensitive to small temperature variations.

\section{CONCLUSIONS}

The purpose of this analysis has been to study the structure of hydrogen-air diffusion flames in the counterfiow configuration for strain conditions that place the system far from extinction, but not so far that dissociation steps contribute. We have seen that Damköhler-number asymptotics provides an adequate description of the flame in this regime, in which the mixing layer can be divided into two radical-free equilibrium regions separated by a thin reaction layer. It was seen that in the outer regions the solution corresponds to the Burke-Schumann limit and can be determined by introduction of generalized coupling functions. Results obtained in this limit, with a simplified description adopted for the flow field, were shown to compare well with those of numerical integrations of the conservation equations with a detailed transport description.

It was seen that in the reaction region the $\mathrm{H}$ atom plays an important role because of its large relative concentration, which is dictated by the large value of the parameter $K_{H}$. The analysis reveals that the maximum $\mathrm{H}$-atom concentration and the decrease in the maximum temperature scale with the one-third power of the strain rate, a fact that was found numerically in previous studies (Lee and Chung, 1994) but has remained unexplained. The present work explains this scaling by identifying the key chemistry that is occuring. Introduction of the parameter $\varphi$ allows us to describe the evolution of the reaction later as the strain rate increases. It was seen that an inner asymptotic structure, consisting of two radical recombination layers and a thin radical production layer, appears for sufficiently large strain rates. A similar asymptotic structure was encountered earlier Lee and Chung (1994), but the kinetic mechanism that was employed and the associated asymptotic scalings that were found differ from those identified here, where the overall five-layer structure emerges as a natural extension of the three-layer structure in the limit $\varphi \rightarrow \infty$.

Comparisons of the results of the asymptotic analysis with those of numerical integrations of the full conservation equations with detailed chemistry showed good 
agreement over a wide range of strain conditions for both undiluted and diluted fuel feed streams. In particular, it was seen that the numerical results follow closely the one-third power scaling law predicted by the asymptotic analysis. Further improvement of the predictions of the asymptotic analysis was obtained by accounting iteratively for chemical-time variations with temperature.

The results of the present analysis are readily applicable to more complex flows, such as turbulent diffusion flames in reaction-sheet regimes. In particular. since the structure of the reaction layer is independent of the external geometrical contiguration, Equations 46 and 48 can be utilized to account for finite-rate effects once the outer convective-diffusive regions have been solved in the Burke-Schumann limit and the peak temperature and the fuel and temperature gradients at the flame have been determined.

Although the study presented here provides an adequate description of the evolution of the flame structure as the strain decreases, more work is necessary to describe the transition of the flame into the extinction regime. Previous analyses (Balakrishan et al, 1992) show that such a description requires relaxation of the partial-equilibrium assumptions for one or more of the shuffle reaction 1-4 and consideration of the influence of temperature on the radical production mechanism. The results presented here also indicate that the reaction region ceases being a thin layer before extinction occurs. It can be concluded that an asymptotic analysis based on a thin reactivediffusive layer separating two convective-diffusive regions is no longer appropriate near extinction, so that consideration of convection, diffusion and chemical reactions occuring simultaneously everywhere in the mixing layer is necessary if accurate predictions are to be obtained.

\section{APPENDIX: NUMERICAL SOLUTION TO EQS. 31 AND 32}

Although numerical integration of the second-order differential Equation 32, supplemented by the nonlinear algebraic Equation 31, is a relatively easy task, finding an efficient shooting scheme requires some preliminary analysis. Equation 31 is quadratic in $y_{\mathrm{O}_{2}}^{1 / 2}$ and can be solved to give

$$
y_{\mathrm{O}_{2}}^{1 / 2}=\frac{\varphi}{8} y_{\mathrm{H}_{2}}^{3 / 2} \pm \sqrt{\left(\frac{\varphi}{8} y_{\mathrm{H}_{2}}^{3 / 2}\right)^{2}+\frac{y_{\mathrm{H}_{2}}+\xi}{2}} .
$$

The positive branch of this expression applies as $\xi \rightarrow \infty$, where $y_{\mathrm{H}_{2}} \rightarrow 0$ and $y_{\mathrm{O}_{2}}^{1 / 2} \rightarrow \sqrt{\xi / 2}$, while one must choose the negative branch to describe the behavior of the solution as $\xi \rightarrow-\infty$, where $y_{\mathrm{O}_{2}}$ must decay to zero. Transition between both branches takes place at a point where the radicand vanishes, so that $\xi$ and $y_{\mathrm{H}_{2}}$ satisfy

$$
\left(\frac{\varphi}{8} y_{\mathrm{H}_{2} t}^{3 / 2}\right)^{2}+\frac{y_{\mathrm{H}_{2} t}+\xi_{t}}{2}=0
$$

with the subscript $t$ denoting values at the transition point. The above equation is cubic in $y_{\mathrm{H}_{2} t}$ and can be seen to posses a single real root for any given $\xi_{t}$. The existence of a transition point embedded in the integration domain clearly suggests that for 
efficiency of integration one must choose $\xi_{t}$, to be determined as part of the solution, as the initial point for the numerical shooting. Also, since variations of $y_{\mathrm{O}_{2}}$ with $\xi$ and $y_{\mathrm{H}_{2}}$ are given explicitly by Equation $\mathrm{A} 1$, it is convenient to adopt $y_{\mathrm{H}_{2}}$ as an integration variable, its governing equation being

$$
\begin{gathered}
\frac{\mathrm{d}^{2}}{\mathrm{~d} \xi^{2}}\left[-y_{\mathrm{H}_{2}}+3\left(\frac{\varphi}{8} y_{\mathrm{H}_{2}}^{3 / 2} \pm \sqrt{\left(\frac{\varphi}{8} y_{\mathrm{H}_{2}}^{3 / 2}\right)^{2}+\frac{y_{\mathrm{H}_{2}}+\xi}{2}}\right)^{2}\right]= \\
\varphi\left(\frac{\varphi}{8} y_{\mathrm{H}_{2}}^{3 / 2} \pm \sqrt{\left.\left(\frac{\varphi}{8} y_{\mathrm{H}_{2}}^{3 / 2}\right)^{2}+\frac{y_{\mathrm{H}_{2}}+\xi}{2}\right)^{3} y_{\mathrm{H}_{2}}^{3 / 2}+}\right. \\
\gamma_{6} \varphi^{2}\left(\frac{\varphi}{8} y_{\mathrm{H}_{2}}^{3 / 2} \pm \sqrt{\left(\frac{\varphi}{8} y_{\mathrm{H}_{2}}^{3 / 2}\right)^{2}+\frac{y_{\mathrm{H}_{2}}+\xi}{2}}\right)^{2} y_{\mathrm{H}_{2}}^{3},
\end{gathered}
$$

obtained by substitution of Equation $\mathrm{A} 1$ into Equation 32. Other choices of integration variables that might seem more natural, such as the combination $-y_{\mathrm{H}_{2}}+3 y_{\mathrm{O}_{2}}$, would involve solution of an implicit algebraic equation to determine the value of $y_{\mathrm{H}_{2}}$ and $y_{\mathrm{O}_{2}}$, which are necessary for evaluation of the right-hand side of Equation 32 at every location across the integration domain, and obtaining such solutions would lengthen the computation time appreciably.

At the transition point the value of $\dot{y}_{\mathrm{H}_{2}}$ must satisfy

$$
3\left(\frac{\varphi}{8}\right)^{2} y_{\mathrm{H}_{2} t}^{2} \dot{y}_{\mathrm{H}_{2} t}+\frac{\dot{y}_{\mathrm{H}_{2} t}+1}{2}=0
$$

necessary to guarantee the condition $\dot{y}_{\mathrm{O}_{2}}<\infty$. Here, as in the main text, the dot indicates differentiation with respect to $\xi$. For a given value of $\xi_{t}$, Equations A2 and A4 uniquely determine the values of $y_{\mathrm{H}_{2 t}}$ and $\dot{y}_{\mathrm{H}_{2} t}$, while the values of $\dot{y}_{\mathrm{O}_{2} t}$ and $\ddot{y}_{\mathrm{H}_{2 t}}$ remain undetermined, that is, if Equation $\mathrm{A} 3$ is solved for $\ddot{y}_{\mathrm{H}_{2}}$, the numerator and denominator of the resultant expression vanish at $\xi=\xi_{t}$. Because of this singular character of the solution at the transition point, integration towards $\pm \infty$ must be initiated a small distance $\pm \varepsilon$ away from $\xi_{t}$. At $\xi_{t}^{ \pm}=\xi_{t} \pm \varepsilon$ the values of $y_{\mathrm{H}_{2}}$ and $\dot{y}_{\mathrm{H}_{2}}$ are given in the first approximation by

$$
y_{\mathrm{H}_{2 t}}^{ \pm}=y_{\mathrm{H}_{2 t}} \pm \dot{y}_{\mathrm{H}_{2 t}} \varepsilon+\ddot{y}_{\mathrm{H}_{2} t} \varepsilon^{2} / 2
$$

and

$$
\dot{y}_{\mathrm{H}_{2} t}^{ \pm}=\dot{y}_{\mathrm{H}_{2 t}} \pm \ddot{y}_{\mathrm{H}_{2 t}} \varepsilon
$$

respectively. Numerical integrations of Equation A3 can be performed from $\xi=\xi_{t}$ towards $\pm \infty$ using the above initial values of $y_{\mathrm{H}_{z}}$ and $\dot{y}_{\mathrm{H}_{2}}$ to determine, in an iterative fashion, the values of $\xi_{t}$ and $\ddot{y}_{\mathrm{H}_{2} t}$ for which the boundary conditions $y_{\mathrm{H}_{2}}(-\infty)=-\xi$ and $y_{\mathrm{H}_{2}}(\infty)=0$ are simultaneously satisfied.

\section{ACKNOWLEDGEMENTS}

This work was supported by the National Science Foundation through Grant No. CTS-92-14888. The wok of A. Liñan nas partially supported by the Spanish CICYT under Project No. ESP-90-013001. GB would like to thank Prof. M. D. Smooke for providing the numerical code used in this study, 
Allison, R. A. and Clarke, J. F. (1980). Theory of a Hydrogen-Oxygen Diffusion Flame, Part I: Profiles from a Large Damkohler Number Model. Combust. Sci. Tech, 23, 113.

Allison, R. A. and Clarke, J. F. (1981). Theory of a Hydrogen-Oxygen Diffusion Flame. Part II: Large Activation Energy Asymptotics. Combust. Sci. Tech., 25, 97.

Balakrishnan, G. (1992). Studies of Hydrogen-Air Diffusion Flame and of Compressibility Effe'ts Reluted to High-Speed Propulsion. Ph.D. Thesis, University of California, San Diego, La Jolla, CA.

Balakrishnan, G., Smooke, M. D. and Williams, F. A. (1995). A Numerical Investigation of Extinction and Ignition Limits in Laminar Nonpremixed Counterflowing Hydrogen-Air Streams for Both Elementary and Reduced Chemistry. Combust. Flame, 102, 329.

Balakrishnan, G., Trees, D. and Williams, F. A. (1994). An Experimental Investigation of Strain-Induced Extinction of Diluted Hydrogen-Air Counterflow Diflusion Flames. Combust. Flame, 98, 123.

Balakrishnan, G., Treviño C. and Mauss, F. (1992). The Asymptotic Strueture of Hydrogen-Air Diffusion Flames. Combust. Flame, 91, 246.

Balakrishnan, G. and Williams, F. A. (1994). Turbulent Combustion Regimes for Hypersonic Flows Employing Hydrogen-Air Diffusion Flames. J. Prop. Power, 10, 434.

Baulch, D. L., Cobos, C. J., Cox, R. A., Esser, C., Frank, P., Just, T., Kerr, J. A., Philling, M. J., Troe, J., Walker, R. W. and Warnatz, J. (1992). Evaluated Kinetic Data for Combustion Modelling. J. Phys. Chem. Ref. Data, 21, 411.

Baulch, D. L., Drysdale, D. D., Horne, D. G. and Lloyd, A. C. (1972). Eualuated Kinetic Datu for High Temperature Reactions. Butterworths, London, Vol. 1.

Bilger, R. W.(1980). Perturbation Analysis of Turbulent Nonpremixed Combustion. Combust. Sci. Tech., 22, 251.

Chelliah, H. and Williams, F. A. (1990). Aspects of Structures and Extinction of Diffusion Fiames in Methane-Oxygen-Nitrogen Systems. Combust. Flame, 80, 17.

Chung, S. H. and Williams, F. A. (1990). Asymptotic Structure and Extinction of CO-H, Diffusion Flames with Reduced Mechanisms. Combust. Flame, 82, 389.

Clarke, J. F. (1968). On the Structure of a Hydrogen-Oxygen Diffusion Flame. Proc. Roy. Soe. London, 307A, 283.

Clarke, J. F. (1969). Reaction-Broadening in a Hydrogen-Oxygen Diffusion Flame. Proc. Roy. Soc. London, $312 \mathrm{~A}, 65$,

Clarke, J. F. and Moss, J. B. (1970). On the Structure of a Spherical $\mathrm{H}_{2}-\mathrm{O}_{2}$ Diffusion Flame. Combust. Sci. Tech, $2,115$.

Dixon-Lewis, G. and Missaghi, M. (1988). Structure and Extinction Limits of Counterfow Diffusion Flames of Hydrogen-Nitrogen Mixtures in Air. In Twenty-Second Symposium (International) on Combustion. The Combustion Institute, Pittsburgh, PA, pp. 1461-1470.

Dixon-Lewis, G. and Williams, D. J. (1977). In Bamford C. H. and Tipper, C. F. H. (Eds.) Comprehensive Chemical Kinetics, EIsevier, London. 17, 109-144.

Giovangigli, V. and Darabiha, N. (1988). Vector Computers and Complex Chemistry Combustion. In Brauner, C. and Schmidt-Lainé, C., (Eds.) Mathematical Modelling in Combustion and Related Topies, NATO Adv. Sci. Inst. Ser. E., 140, 491-503.

Giovangigli, V. and Smooke, M. D. (1989). Adaptive Continuation Algorithms with Application to Combustion Problems. Applied Numerical Mathematics, 5, 305.

Gutheil, E., Balakrishnan, G. and Williams, F. (1993). Structure and Extinction of Hydrogen-Air Diffusion Flames. In Peters, N, and Rogg, B., (Eds.) Reduced Kinetic Mechanisms for Applications in Combustion Systems, Springer Verlag, Germany. Chap. 11, pp. 177-195.

Gutheil, E. and Williams, F. (1990). A Numerical and Asymptotic Investigation of Structures of HydrogenAir Diffusion Flames at Pressures and Temperatures of High-Speed Propulsion. In Twenty-Third Symposium (International) an Combustion, The Combustion Institute, Pittsburgh, PA, pp. 513-521.

Hewson, J. C. and Williams, F. A. (1994). CO and $\mathrm{NO}_{x}$ Emissions from a Laminar Coflow Diffusion Flame: A Comparison of Experimental and Theoretical Results. Paper No. 46 Presented at the Technical Meeting of the Western States Section of the Combustion Institute, U. C. Davis, Davis, CA, March $21-22,1994$.

Hirschfelder, J. O., Curtiss, C. F. and Bird, R. B. (1954). Molecular Theory of Gases and Liquids. John Wiley and Sons, New York.

Ishizuka, S. and Tsuji, H. (1981). An Experimental Study of Effect of Inert Gases on Extinction of Laminar Diffusion Flames. In Eighteenth Sympositum (International) on Combustion, The Combustion Institute, Pittsburgh, PA, pp. 695-703.

Kee, R. J., Warnatz, J. and Miller, J. A. (1983). A General-Purpose; Problem-Independent, Transportable, Fortran Kinetics Code Package. Technical Report UC-32, SAND83-8209, Sandia, Livermore, CA. 
Keyes, D. E. and Smooke, M. (1987). Flame Sheet Starting Estimates for Counterflow Diffusion Flame Problems. Journal of Computational Physics, 73, 267.

Kim, J. S. and Williams, F. A. (1990). Theory of Counterflow Mixing of Fuel with Hot Reaction Products. Combust. Sci. Tech., 73, 575 .

Lee, S. R. and Chung, S. H. (1994). On the Structure of Hydrogen Diffusion Flames with Reduced Kinetic Mechanisms. Combust. Sci. Tech., 96, 247.

Liñán, A. and Williams, F. A. (1993). Fundamental Aspects of Combustion. Oxford University Press, New York, NY, 1st edition, pp. 144-146.

Liñán, A., Orlandi, P., Verzicco, R. and Higuera, J. (1994). Effects of Non-Unity Lewis Numbers in Diffusion Flames. Proceedings of the 1994 Summer Program. Center for Turbulence Research, NASA Ames/Stanford Univ., pp. 5-18.

Mansten, D. A., Hanson, R. K. and Bowman, C. T. (1990). Shock Tube Study of the Reaction $\mathrm{H}+\mathrm{O}_{2} \rightarrow \mathrm{OH}+\mathrm{O}$ Using Laser Absorption. J. Phys. Chem., 94, 7119.

Pellet, G. L., Northan, G. B. and Wilson, L. G. (1991). Counterflow Diffusion Flames of Hydrogen and Hydrogen Plus Methane, Ethylene, Propane and Silane vs. Air: Strain Rates at Extinction. Al A A Paper. 91-0370.

Pellet, G. L., Northam, G. B. and Wilson, L. G. (1992). Strain-Rate Induced Extinction of Hydrogen-Air Counterflow Diffusion Flames: Effect of Steam, $\mathrm{CO}_{2}, \mathrm{~N}_{2}$ and $\mathrm{O}_{2}$ Additives to Air. AI AA Paper, 92-0877.

Sánchez, A. L. (1995). Bifurcation and Asymptotic Analyses of Hydrogen-Air Diffusion Flames Ph.D. Thesis, University of California, San Diego, La Jolla, CA.

Seshadri, K. and Peters, N. (1988). Asymptotic Structure and Extinction of Methane-Air Diffusion Flames. Combust. Flame, 73, 23.

Smooke, M. D. (1991). Reduced Kinetic Mechanisms and Asymptotic Approximations for Methane-Air Flames. Springer-Verlag, New York, NY.

Smooke, M. D., Puri, I. K. and Seshadri, K. (1988). The Structure and Extinction of Partially Premixed Flames Burning Methane in Air. In Twenty-Second Symposium (International) on Combustion, The Combustion Institute, Pittsburgh, PA, pp. 1555-1563.

Tangirala, V., Seshadri, K., Treviño, C. and Smooke, M. D. (1991). Analysis of the Structure of Counterflow Hydrogen-Air Diffusion Flames. Progress in Astronautics and Aeronatutics, AIAA, 131, 89.

Trees, D., Brown, T. M., Seshadri, K., Smooke, M. D., Balakrishnan, G., Pitz, R. W., Giovangigli, V. and Nandula, S. P. (1994). The Structure of Nonpremixed Hydrogen-Air Flames, Combust. Sci. and Tech., $104,427$.

Treviño, C. and Mauss, F. (1993). Structure and Extinction of Nondiluted Hydrogen-Air Diffusion Flames. In Peters, N. and Rogg, B. (Eds.) Reduced Kinetic Mechanisms for Applications in Combustion Systems, Springer Verlag, Germany, Chap. 10, pp. 159-176.

Treviño, C. and Williams, F. A. (1988). Asymptotic Analysis of the Structure and extinction of Methane-Air Diffusion Flames. Progress in Astronautics and Aeronautics, AIAA, 113, 129.

Warnatz, J. (1984). Towards a Quantitative Consistent Scheme for the Oxidation of Hydrogen, Carbon Monoxide, Formaldehyde and Methane in Flames. In Gardiner, W. C. (Ed.) Combustion Chemistry, Springer, New York, pp. 197-360.

Williams, F. A. (1985), Combustion Theory, Benjamin Cummings, Menlo Park, CA, 2nd edition, pp. $489-495$.

Yetter, R. A., Dryer, F. L. and Rabitz, H. (1991). A Combined Stability-Sensitivity Analysis of Weak and Strong Reactions of Hydrogen/Oxygen Mixtures. Combust. Sci. Tech., 79, 97. 